Emilio Bouza ${ }^{1 *}$

Miguel Martín Jiménez ${ }^{2 *}$

Laia Alemany ${ }^{3}$

Joaquín Arribas ${ }^{4}$

Rafael Bañares ${ }^{5}$

$M^{a}$ Begoña Barragán ${ }^{6}$

José María Eiros Bouza ${ }^{7}$

Enriqueta Felip ${ }^{8}$

Oscar Fernández-Capetillo ${ }^{9}$

Diego Gracia ${ }^{10}$

Rogelio López-Vélez"11

Juan Bautista Mollar ${ }^{12}$

Patricia Muñoz ${ }^{13}$

Luis Paz-Ares ${ }^{14}$

Aureli Torné15

Javier Tovar ${ }^{16}$

Eulalia Valencia ${ }^{17}$

Esteban Palomo ${ }^{18}$

\section{Overview of virus and cancer relationships. Position paper}

'Department of Medicine, Universidad Complutense. Department of Clinical Microbiology and Infectious Diseases, Hospital General Universitario Gregorio Marañón, Gregorio Marañón Health Research Institute, and Respiratory Diseases CIBER (CIBERES CB06/06/0058), Madrid.

${ }^{2}$ Department of Medicine, Universidad Complutense. Head of the Oncology Department, Hospital General Universitario Gregorio Marañón, Gregorio Marañón Health Research Institute, Madrid.

${ }^{3}$ Cancer Epidemiology Research Programme. Instituto Catalán de Oncología, IDIBELL. Barcelona; CIBERESP

${ }^{4}$ Catalan Institution for Research and Advanced Studies (ICREA). Director of the Preclinical Research Programme, Vall d'Hebron Oncology Institute (VHIO), Barcelona. Scientific Director of CIBERONC.

${ }^{5}$ Department of Medicine, Universidad Complutense. Head of the Gastroenterology Department at the Hospital General Universitario Gregorio Marañón. Madrid. CIBER of Diseases of the Digestive System.

${ }^{6}$ Spanish Cancer Patient Group, GEPAC.

${ }^{7}$ Universidad de Valladolid. Head of the Microbiology Department at the Hospital Universitario Rio Hortega. Valladolid. ${ }^{8}$ Hospital Vall d'Hebron. Barcelona

${ }^{9}$ Director of the Molecular Oncology Programme, Head of the Genomic Instability Group, National Cancer Research Centre (CNIO), Madrid, Spain. Professor of Antitumour Therapies, Karolinska Institute, Stockholm, Sweden.

${ }^{10} \mathrm{Faculty}$ of Medicine of the Complutense University of Madrid. President of the Health Sciences Foundation. Madrid.

${ }^{11}$ National Centre for Expertise in Tropical Diseases of the Infectious Diseases Department of the Hospital Universitario Ramón y Cajal in Madrid.

${ }^{12}$ Preventive Medicine Department, Hospital La Fé, Valencia.

${ }^{13}$ Department of Medicine, Universidad Complutense, Madrid (UCM), Department of Clinical Microbiology and Infectious Diseases, Hospital General Universitario Gregorio Marañón, Gregorio Marañón Health Research Institute, and Respiratory Diseases CIBER (CIBERES CB06/06/0058), Madrid.

${ }^{14}$ Medical Oncology Department, Hospital Universitario 12 de Octubre. Department of Medicine. Complutense University. Madrid.

${ }^{15}$ Gynaecological Oncology Unit. ICGON Endocrinology, Gynaecology and Human Reproduction_IDIBAPS Hospital Clinic de Barcelona

${ }^{16}$ EFE Salud.

${ }^{17}$ Internal Medicine Department - HIV Unit. Hospital Universitario La Paz. Madrid.

${ }^{18}$ Health Sciences Foundation. Madrid

Article history

Received: 27 April 2021; Accepted: 15 May 2021; Published: 5 August 2021

\section{ABSTRACT}

The role of certain viruses in the etiology of some tumors is today indisputable, but there is a lack, however, of an overview of the relationship between viruses and cancer with a multidisciplinary approach. For this reason, the Health Sciences Foundation has convened a group of professionals from different areas of knowledge to discuss the relationship between viruses and cancer, and the present document is the result of these deliberations. Although viruses cause only 10-15\% of cancers, advances in oncology research are largely due to the work done during the last century on tumor viruses. The

Correspondence:

Emilio Bouza MD, PhD

Gregorio Marañón Health Research Institute.

C/ Dr. Esquerdo, 46

28007 Madrid, Spain

Telephone: +34- 91- 58684 53/Fax: +34- 91 - 5044906

E-mail:emilio.bouza@gmail.com

Alternative corresponding author

Esteban Palomo, PhD.

Director. Fundación de Ciencias de la Salud.

C/ Severo Ochoa, 2

28760 Tres Cantos. Madrid

Telephone: +34 913530150

*Both authors have equally contributed to this work clearest cancer-inducing viruses are: HPV, HBV, HCV, EBV and, depending on the geographical area, HHV-8, HTLV-1 and HIV. $H P V$, for example, are considered to be the causative agents of cervical carcinomas and, more recently, of a proportion of other cancers. Among the Herpes viruses, the association with the development of neoplasms is well established for EBV and HHV-8. Viruses can also be therapeutic agents in certain neoplasms and, thus, some oncolytic viruses with selective tropism for tumor cells have been approved for clinical use in humans. It is estimated that the prophylaxis or treatment of viral infections could prevent at least 1.5 million cancer deaths per year.

Keywords: Virus, Cancer, Tumours, Human Papillomavirus, HPV, Hepatitis B, Hepatitis C. HBV, HCV, Epstein-Barr Virus, EBV, Human Herpes Virus 8, HHV-8, Human T Lymphotropic Virus I, HTLV-1, Human Immunodeficiency Virus, HIV, Vaccines, Oncolytic virus, Oncogenes, Cancer mortality, Cancerprevention, Cancer-economy

\section{Visión general de las relaciones entre virus y cáncer: documento de posición}

\section{RESUMEN}

El papel de ciertos virus en la causalidad de algunos tu- 
mores es hoy indiscutible, pero se carece, sin embargo, de una visión general de las relaciones virus y cáncer con una aproximación multidisciplinar. Por ello, la Fundación de Ciencias de la Salud ha convocado a un grupo de profesionales de distintas áreas del conocimiento para discutir sobre la relación virus y cáncer y el presente documento es el resultado de dichas deliberaciones. A pesar de que los virus causan sólo un 10-15\% de los cánceres, los avances en la investigación oncológica se deben, en gran medida, al trabajo que se realizó durante el siglo pasado sobre los virus tumorales. Los virus más claramente inductores de cáncer son: $\mathrm{VPH}, \mathrm{VHB}, \mathrm{VHC}, \mathrm{VEB}$ y, en función de la zona geográfica, VHH-8, HTLV-1 y VIH. Los VPH, por ejemplo, se consideran los agentes causantes de los carcinomas de cérvix y, más recientemente, de una proporción de otros cánceres y entre los virus Herpes, la asociación con el desarrollo de neoplasias está bien establecida para VEB y VHH-8. Los virus pueden ser también agentes terapéuticos en determinadas neoplasias y, asi, algunos virus oncolíticos con tropismo selectivo para células tumorales, han sido aprobados para su uso clínico en humanos. Se estima que la prevención o tratamiento de las infecciones virales podría evitar no menos de un millón y medio de muertes anuales por cáncer.

\section{INTRODUCTION}

The success in human longevity achieved in recent decades is impressive and could be even greater if the major challenges of neurodegenerative diseases, cardiovascular disease and cancer could be controlled.

Of the three challenges above, cancer treatment is perhaps achieving more success than the other two, not only because of better prevention and earlier diagnosis, but also because of increasingly effective and better-tolerated treatment.

Viruses offer a first approximation to the aetiological diagnosis in the case of cancer and the role some of them play in the pathogenesis of certain tumours is today indisputable. Their prevention, such as in the case of HPV and cervical cancer, has radically changed our expectations for the future and allows us to envision the eradication of this tumour. Unfortunately, the virus-cancer relationship is not so clear-cut in many other tumours and when we look for global data on that relationship, we find scattered and inaccurate, irregular literature of a very uneven nature and quality.

For this reason, the Health Sciences Foundation has proposed examining the virus-cancer relationship more general$l y$, in a multidisciplinary forum, aiming to obtain answers to a series of simple questions from experts in different aspects of the problem. This meeting has included oncologists, gastroenterologists, internists, gynaecologists, specialists in infectious diseases and HIV, microbiologists, basic biologists, representatives of patient associations and the media, and specialists in preventive medicine and ethics.

A first block of questions was aimed at putting the dimension of the Virus-Cancer relationship, the cancers most clearly caused by viruses, the great historical milestones of this re- lationship and some aspects of oncogenesis into perspective.

In a second block, some potential solutions ranging from vaccines to the treatment of hepatitis $C$ were addressed and the possible role of bacteria and parasites as alternative oncogenic agents was also discussed. We also wanted to understand the importance that cancer patient associations place on this relationship, the understanding that the media has of the problem and the ethical aspects that all this raises.

\section{MATERIAL AND METHODS}

The members of the Board of Trustees of the Health Sciences Foundation proposed a series of questions on the relationship between viruses and cancer that would answer the main uncertainties of the problem at present. The questions were accepted by a multidisciplinary panel of experts. Each question was reported by one of the experts and subsequently the text and its conclusions were discussed by the working group until conclusions were reached that were accepted by all.

We now turn to the questions and their development. The views expressed are not intended to set out any particular recommendation or therapeutic indication and represent only the opinion of the group's speakers and not necessarily that of the institutions in which they work.

\section{QUESTION: WHAT ARE THE MAJOR HISTORICAL MILESTONES IN THE VIRUS AND CANCER RELATIONSHIP?}

In the early 1970s, most tumours were assumed to be caused by viruses, so much of the research into cancer revolved around tumour viruses. This assumption was eventually discarded and today it is estimated that only 10-15\% of cancers are caused by viruses. However, research into viruses and cancer, the milestones of which are summarised below, proved decisive in understanding the aetiology of the disease [1-4].

\section{Discovery of the avian sarcoma virus}

In the early 1900s, Peyton Rous, working at the Rockefeller Institute in New York, showed that a type of sarcoma affecting chickens was transmissible through homogenate filtrates that could only contain viruses. Years later, the causative virus was isolated and named Rous Sarcoma Virus (RSV). This discovery marks the beginning of research into tumour viruses.

\section{Transformation in cell cultures}

During the 1960s, Harry Rubin and Howard Temin managed to establish a new experimental model to study tumour viruses at the California Institute of Technology. It consisted of the infection of fibroblasts in culture with the Rous Sarcoma Virus. The infection caused radical changes in the phenotype of the cells, which acquired capacities characteristic of tumour cells, such as: reduced dependence on growth factors, immortality, anchorage-independent growth, motility, invasiveness, 
loss of contact inhibition, metabolic reprogramming and the ability to form tumours in syngeneic or immunosuppressed mice. These changes were called cellular transformation. The new experimental system ushered in a new era in tumour virus research $[5,6]$.

\section{Discovery of DNA tumour viruses}

In 1960, at the Rockefeller Institute in New York, Richard Shope identified the virus that causes papillomas in rabbits. Papillomas are benign tumours that rarely progress to squamous cell carcinomas of the skin. Unlike Rous Sarcoma Virus, whose genetic material is RNA, papillomaviruses are made of DNA. There are currently more than 100 human papillomaviruses (HPV) described. The discovery of HPV was followed by the discovery of more tumour viruses whose genetic material is DNA, including: i) Polyomavirus, which when infecting mice caused tumours of various origins, hence its name, ii) Simian Virus 40 (SV40), which is a lytic virus in some primate cell types and silent in rodent cells and is therefore called non-permissive. In non-permissive cells, SV40 produces cellular transformation, although at a very low frequency [7-9].

Papillomavirus, polyomavirus, and SV40 are known as papovaviruses. Their DNA is a small circular molecule.

Other viruses with oncogenic capabilities include: i) Adenovirus, which infects the airways and can produce tumours when it infects hamster cells, ii) Herpesvirus, which produces different tumours in human cells, iii) Epstein Barr Virus (EBV), which can produce Burkitt's lymphomas or nasopharyngeal carcinomas. Compared to the papovaviruses, the latter three are very large.

\section{Integration of the virus into the host cell genome}

Several lines of evidence showed that the tumour viruses had to remain active in the tumour cells to maintain the transformed phenotype. The inactivation of the virus produced a return to the normal cellular state.

Different viruses use different mechanisms to keep tumour cells from dividing after division. Some, like EBV or HPV, become integrated, becoming a part of the cell genome. Almost all cervical tumours are produced by HPVs, which make up the part of their genome necessary for cell transformation (the E6 and E7 oncogenes) [10].

Herpesviruses use two strategies to perpetuate their genome in tumour cells. Some, such as human herpesvirus- 6 $(\mathrm{HHV}-6)$ integrate into the telomeric regions of the chromosomes, which are transcriptionally silenced, making the virus able to remain latent for long periods of time. Others, such as the herpesvirus that produces Kaposi's sarcoma (HHV-8), replicate episodically, i.e., extrachromosomally, but are able to bind to chromosomes temporarily to ensure replication.

While DNA virus integration solved how they could remain in the tumour cells, it created a seemingly unsolvable problem. How did RNA viruses like Rous Sarcoma Virus remain? The solution to this problem led to one of the most surprising discoveries in biology: retrotranscription. Howard Temin and
David Baltimore showed that RNA viruses copy their genome into double-stranded DNA, which integrates into the host cell's genome. Retrotranscription violated the dogma proposed by Francis Crick by which the flow of biological information follows the DNA-RNA-Protein direction. In fact, retrotranscription is a mandatory step in the life cycle of retroviruses;as the RNA viruses that undergo this process are called. In contrast, the integration of DNA viruses is a very rare event $(<1$ in 1,000 infections).

\section{Identifying the first of a long list of oncogenes}

Rous Sarcoma Virus, like most retroviruses, has a reduced genome ( 10 kb). In it are encoded the genes necessary for its retrotranscription and integration, as well as the proteins that form part of its capsid. This simplicity made them very useful tools in identifying the elements required for cell transformation. By comparing viral variants capable of replication but not transformation, with variants capable of transformation but not replication, it was concluded that a single gene, called src, was responsible for cell transformation.

Characterising the src oncogene, in 1974 Harold Varmus and Michael Bishop, working at the University of California, San Francisco, obtained a totally unexpected result [11-13]. They found copies of src in cells that had not been transformed by Rous Sarcoma Virus. Actually, src is a gene present in totally normal cells that was hijacked by the tumour virus Rous Sarcoma Virus. This result was an authentic revolution and led to several conclusions that have revolutionised the way we think about cancer, some of which are detailed below:

- The cellular version of src, known as c-src had to play a role in the homeostasis of healthy cells.

- An ancestral form of the Rous Sarcoma Virus acquired the src after infecting a normal cell. In fact, there is ALV (avian leukosis virus) which is infectious but not tumoral and has the same genes as Rous Sarcoma Virus, except src.

- The identification of c- and v-src opened the possibility that in the normal genome there were numerous proto-oncogenes that could have been co-opted by other tumour retroviruses.

- A single oncogene, v-src was sufficiently pleiotropic to modify the 20-30 characteristics that differentiate a normal cell from a tumour cell.

The discovery of src initiated a race to identify oncogenes carried by retroviruses, which led to the characterisation of oncogenes involved in the pathogenesis of numerous tumours. These are two examples:

- The avian myelomatosis virus, which produces transformation of marrow cells by means of the $v$-myc oncogene. In this case the original non-tumour virus was also the AVL.

- The Harvey and Kirsten sarcoma viruses, which led to the identification of the H-Ras and K-Ras oncogenes.

Currently the list of oncogenes associated with retroviruses exceeds two dozen [14]. 


\section{Conclusion}

Despite the fact that viruses cause only 10-15\% of cancers, advances in the understanding of this disease are largely due to research that has been conducted over the past century on tumour viruses. For example, oncogenes were discovered through research into the Rous sarcoma virus.

\section{QUESTION: AT PRESENT, WHAT PROPORTION OF MALIGNANT TUMOURS IN GENERAL HAVE A PROVEN OR PROBABLE CAUSALITY IN A VIRAL INFECTION?}

It is accepted that one out of six tumours in the world is probably associated with an infection. It is important to highlight that in the series published on this subject, the sources of information and the criteria for detecting infectious agents are heterogeneous and this conditions the reliable approach to the subject.

The International Agency for Research on Cancer (IARC) in Lyon [15] through the Epidemiology and Infections Group has made significant contributions that underpin some of the current knowledge in this area. In a study by Plummer et al [16], published with data from 2012, it is established that of the 14 million new cases of cancer per year, 2.2 million (15.4\%) were attributed to infections. Excluding one bacterium (Helicobacter pylori with 770,000 cases), which proved to be predominant, the next four most important infectious agents worldwide were HPV (640,000), Hepatitis B Virus (HBV, 420,000), Hepatitis C Virus (HCV, 170,000) and EBV $(120,000)$. Furthermore, in sub-Saharan Africa, Kaposi's Sarcoma (caused by HHV-8) emerged as the second largest contributor to the cancer burden. In 2008, there were 7.5 million deaths from this type of tumour. Two-thirds of these deaths occur in poor countries. To these can be added the role of certain retroviruses linked to oncogenic capabilities such as HTLV-1 and Human Immunodeficiency Viruses (HIV) [17].

It should be noted that the role of the virus as an aetiological agent of tumours is conditioned by its prevalence, by its detection methods and by the estimation of the attributable risk in exposed populations. The accuracy of the measurement of exposure is critical as it ensures that the different methods for calculating attributable risk provide results that are compatible with reality. The experience of the "Global burden of cancers attributable to liver flukes" group shows that infections capable of becoming carcinogenic have demonstrated that biomarkers that are sensitive and capable of distinguishing high-risk from low-risk infections are essential in elucidating the true strength of their role in cancer $[18,19]$.

In the light of the contributions made in this regard, it seems appropriate to refer to an assessment of the cancer burden in France in 2015 attributable to infectious agents [20]. The authors conduct a systematic review of representative series on the prevalence of infectious agents in the main associated cancer types. They tracked original studies published up to September 2016 in PubMed and performed a random-effects meta-analysis. Cancer incidence data were obtained from the French Network of Cancer Registries, allowing the calculation of national incidence estimates in accordance with validated methods. Of the 352,000 new cancer cases in France in 2015, 14,336 (4.1\% of all new cancer cases) were attributable to infectious agents. The largest contribution by infectious agents was represented by HPV and Helicobacter pylori, responsible for 6,333 and 4,406 new tumour cases (1.8 and 1.3\% of all new cancer cases) respectively.

An additional aspect that supports the robustness of the contributions is that three main groups of infectious agents and cancer modalities were used for the estimation of tumours attributable to the infection. Firstly, cancer sites where infectious agents are assumed to contribute to almost 100\% of all cases (cervical cancer due to high-risk HPV). Secondly, cancer sites attributable to infection whenever the infectious agent is detected in the tumour tissue using sensitive and validated detection methods (oral, oropharyngeal, anal, laryngeal, vulvar, vaginal and penile cancers due to highrisk HPV; nasopharyngeal cancers, Hodgkin's and non-Hodgkin's lymphomas due to EBV and - although it is a bacterial infection - gastric MALT Iymphoma due to $H$. pylori). Thirdly, cancer cases where infectious agents increase the risk of developing a tumour, but are not responsible for all new cancer cases, even when antibodies to the infectious agent are detected in the serum.

The proportion of new cancer cases in France associated with infectious agents is comparable to that of other highincome countries $[21,22]$. The estimates of this study are overall slightly higher (4.1\%) than those of the specific analyses for the United Kingdom [21] and Australia [22] in 2010, where gender categorisation showed that 2.5\% and $2.4 \%$ of all new cancer cases among men were attributable to infectious agents in both countries, respectively, and $3.5 \%$ and $3.7 \%$ of all new cancer cases among women were also attributable to infectious agents. These differences with previous studies are due, in part, to differences in the risk of infection between areas, as well as differences in what is considered the gold standard for measuring the prevalence of infection in association with specific cancers [23].

There are important global differences, depending on health and sociocultural conditions, in how these infections are responsible for tumour genesis. Thus, in Australia and New Zealand the infectious origin of a cancer is in 3.3\% of cases compared to $32.7 \%$ in Sub-Saharan Africa [24]. Improving the quality and quantity of knowledge seems essential so as to prioritise preventive programmes and reduce the disease burden.

\section{Conclusion}

It is estimated that one in six tumours in the world is probably or demonstrably associated with an infection. The role of viruses as an aetiological agent of tumours is conditioned by their prevalence, detection methods and the estimate of attributable risk in exposed populations. The most relevant agents are HPV, HBV, HCV, EBV and depending on the zone HHV-8, HTLV-1 and the Human Immunodeficiency Viruses. 


\section{QUESTION: WHICH ARE THE TUMOURS WITH THE MOST CLEARLY DEMONSTRATED VIRAL AETIOLOGY?}

Infections by certain microorganisms (viruses, bacteria, and parasites) are risk factors for developing certain cancers. According to the latest update of the IARC monograph on biological agents associated with cancer, the following microorganisms were classified as carcinogenic (group 1) (Table 1).

In 2016, the estimate of the burden of cancers associated with infectious agents was published [17]. In this estimate, the number of new cases diagnosed in 2012 attributed to the infections previously described in the table by country was calculated by combining the incidence rates of the different cancers with estimates of the attributable fractions of the different infectious agents. The attributable fractions for each infection are calculated with the infection prevalence in cancer cases and the relative risk. These attributable fractions are highly variable depending on the infectious agent and country. Of 14 million new cancer cases diagnosed in 2012, according to GLOBOCAN 2012, 2.2 million (15\%) were attributable to infections. This percentage varies greatly by region, from $5 \%$ in the USA, Canada, Australia and some European countries, to over 50\% in some Sub-Saharan African countries. The most important infectious agents were Helicobacter pylori (770,000 cases), HPV (640,000 cases), HBV (420,000 cases), HCV (170,000 cases) and EBV (120,000 cases). For many of these infections-cancers there are clearly effective preventive strategies such as vaccines and early detection programmes. Vaccination and early detection programmes with treatment should be established to reduce the incidence of these cancers associated with infections.

\section{Conclusion}

Overall, 15\% of cancers are associated with an infectious causal agent. The most important viral agents according to the number of new cancer cases diagnosed are Human Papilloma Virus, Hepatitis B Virus, Hepatitis C Virus and Epstein-Barr Virus.

There are major differences in the incidence of these tumours according to geographical region and socio-economic development.

Vaccines and early detection programmes could dramatically reduce the incidence of cancer associated with viruses, such as HPV and hepatitis B and C viruses.

\begin{tabular}{|c|c|c|c|}
\hline $\begin{array}{l}\text { Infectious age } \\
\text { Oncology. } 200\end{array}$ & $\begin{array}{l}\text { ents associated with cancer. } \\
09\end{array}$ & dapted from Monograph & Review IARC; The Lancet \\
\hline Group 1. Agent & $\begin{array}{l}\text { Cancers with sufficient evidence of } \\
\text { association in humans }\end{array}$ & $\begin{array}{l}\text { Cancers with limited evidence of } \\
\text { association in humans }\end{array}$ & Mechanistics \\
\hline Epstein-Barr virus (EBV) & $\begin{array}{l}\text { Nasopharyngeal cancer, Hodgkin's } \\
\text { lymphoma, Burkitt's lymphoma }\end{array}$ & $\begin{array}{l}\text { Gastric carcinoma, lymphoepithelioma- } \\
\text { like carcinoma }\end{array}$ & $\begin{array}{l}\text { Cell proliferation, apoptosis inhibition, } \\
\text { genomic instability, cell migration }\end{array}$ \\
\hline Hepatitis B virus (HBV) & Liver cancer & $\begin{array}{l}\text { Non-Hodgkin's lymphoma, } \\
\text { cholangiocarcinoma }\end{array}$ & $\begin{array}{l}\text { Inflammation, liver cirrhosis, chronic } \\
\text { hepatitis }\end{array}$ \\
\hline Hepatitis C virus (HCV) & Liver cancer, non-Hodgkin's lymphoma & Cholangiocarcinoma & Inflammation, liver cirrhosis, liver fibrosis \\
\hline $\begin{array}{l}\text { Kaposi's Sarcoma associated Herpesrvirus } \\
\text { (HHV-8) }\end{array}$ & $\begin{array}{l}\text { Kaposi's sarcoma, primary cavity } \\
\text { lymphoma }\end{array}$ & Castleman's disease & $\begin{array}{l}\text { Cell proliferation, apoptosis inhibition, } \\
\text { genomic instability, cell migration }\end{array}$ \\
\hline Human Immunodeficiency Virus (HIV) & $\begin{array}{l}\text { Kaposi's sarcoma, Hodgkin's lymphoma, } \\
\text { non-Hodgkin's lymphoma, cancer of the } \\
\text { cervix, anus, conjunctiva }\end{array}$ & $\begin{array}{l}\text { Cancer of the vulva, vagina, penis, liver, } \\
\text { non-melanoma skin cancer }\end{array}$ & Immunosuppression (indirect mechanism) \\
\hline High-risk Human Papillomavirus (HPV) & $\begin{array}{l}\text { Carcinoma of the cervix, vulva, vagina, } \\
\text { penis, anus, oropharynx, oral cavity and } \\
\text { larynx }\end{array}$ & - & $\begin{array}{l}\text { Immortalisation, genomic instability, } \\
\text { inhibition of DNA repair response, anti- } \\
\text { apoptotic activity }\end{array}$ \\
\hline Human T-cell Lymphotropic Virus (HTLV) & Adult T-cell leukaemia and lymphoma & - & $\begin{array}{l}\text { Immortalisation and transformation of } \\
\text { T-cells }\end{array}$ \\
\hline Helicobacter pylori & Gastric Carcinoma & - & $\begin{array}{l}\text { Inflammation, oxidative stress, altered } \\
\text { cell proliferation and gene expression, } \\
\text { mutation, methylation }\end{array}$ \\
\hline Clonorchis sinensis & Cholangiocarcinoma & - & $\begin{array}{l}\text { Inflammation, oxidative stress, cell } \\
\text { proliferation }\end{array}$ \\
\hline Opisthorchis viverrini & Cholangiocarcinoma & - & $\begin{array}{l}\text { Inflammation, oxidative stress, cell } \\
\text { proliferation }\end{array}$ \\
\hline Schistosoma haematobium & Urinary Bladder Cancer & - & $\begin{array}{l}\text { Inflammation, oxidative stress, cell } \\
\text { proliferation }\end{array}$ \\
\hline
\end{tabular}




\section{QUESTION: IS IT POSSIBLE TO BROADLY UNDERSTAND THE PATHOGENESIS OF VIRUS- MEDIATED ONCOGENESIS? WHAT ARE BRADFORD HILL'S PRINCIPLES OF CAUSALITY?}

As described above, viruses can transform normal cells into tumour cells by activating oncogenes. In some cases, such as Rous Sarcoma Virus, the virus itself contains the oncogene. In others, such as EBV, the virus causes the proliferation of lymphoid cells that eventually remodel their genome so that the expression of the c-Myc oncogene becomes aberrantly high. HPVs integrate pieces of their genome randomly into cells. When these pieces include the oncogenes E6 and E7, they transform the cells, as happens in the vast majority of cervical and some oropharyngeal tumours $[2-4,7,14,25-31]$.

In 1965, Sir Austin Bradford Hill [1] listed nine principles that must be demonstrated epidemiologically in order to establish a causal relationship between an event and the observed effect. Bradford Hill's principles of causality have been used frequently in public health research. None of the principles proves a causal relationship per se; the more principles are fulfilled, the more the notion of a causal relationship is strengthened. Of particular relevance was the application of Bradford Hill principles in the demonstration of the causal relationship between tobacco use and cancer.

The following is a list of principles and how they demonstrate the recently proposed cause-and-effect relationship between HPV and oropharyngeal tumours [10]:

1. The power of the association. While a small association does not mean that there is no causal effect, a larger association makes it more plausible. For example, the risk of oral squamous cell cancer is 2.8 times higher in patients infected with certain strains of HPV.

2. Consistency. If the findings of different observers in different populations are consistent, the probability of causality increases. Different independent studies, conducted in entirely different populations, came to the same conclusion about the relationship between HPV and oral cancers.

3. Specificity. HPV is associated with oropharyngeal cancers, where HPV infections have been identified.

4. Temporality. The effect has to occur after the cause. HPV infections precede the development of oropharyngeal tumours. In fact, the longer the infection has lasted, the greater the risk of cancer.

5. Biological gradient. Greater exposure should generally lead to greater incidence of the effect. However, in some cases, the mere presence of the factor can trigger the effect. In the case of HPV infections the gradation is difficult to establish.

6. Plausibility. A mechanism that explains how the cause can generate the possible effect is very useful, although it depends on the state of our knowledge. The fact that HPV contains oncogenes, whose action mechanism is very well characterised, increases the possibilities of a causal relationship.

7. Coherence. Coherence between epidemiological and laboratory findings increases the likelihood of causality. HPV oncogenes can transform cells in the laboratory.

8. Experimental evidence. It's very much related to the previous point. There is ample experimental evidence of the ability of HPV to direct malignant transformation in various experimental models.

9. Analogy. The effect is seen in analogous situations. Certain oncogenic variants of HPV, such as HPV16, have a clear causal relationship with oral cancer, while very low tumourigenic variants are difficult to find in this type of tumour.

\section{Conclusion}

The Bradford Hill principles are a widely used tool for establishing a causal relationship between an event and a disease. Some tumour viruses such as the Human Papilloma Virus meet these criteria and are therefore considered to be the causative agent of cervical and, more recently, oropharyngeal carcinomas.

\section{QUESTION: HOW COULD THE INVOLVEMENT OF HPV IN GENITAL TUMOURS BE SUMMED UP IN FIGURES?}

HPV is one of the main causative agents of cancer as it is implicated in $4.5 \%(640,000$ cases $)$ of all new cancer cases worldwide each year (8.6\% women; $0.9 \%$ men). It is estimated that in 2012 it caused more than half of all cancers attributable to infections in women (570,000 cases) [32]. The vast majority of HPV-related neoplasms develop in the anogenital tract (primarily cancer of the cervix and less frequently cancer of the vagina, vulva, and anus).

Cervical cancer is the fourth most common cancer among women and the fourth leading cause of cancer death worldwide (the second in women aged 15-44). In 2012 the number of new cases was estimated at 528,000 and the number of deaths at 266,000 [33]. More than $84 \%$ of the cases are diagnosed in developing countries. The age-standardised incidence rate is 14.0 cases and the mortality rate is 6.8 deaths per 100,000 women/ year, with large variations between geographical regions and countries, especially depending on the extent of screening.

All other anogenital cancers that affect both women and men have a lower incidence. Worldwide, 115,000 cases are diagnosed, of which 68,500 are attributable to HPV. In men, 30,000 cases are diagnosed $(17,000$ in the anus and 13,000 in the penis) and in women 38,500 cases $(18,000$ in the anus, 8500 in the vulva and 12,000 in the vagina) [32]. In both the penis and the vulva there is a clear distinction between basaloid or "warty" tumours clearly causally related to HPV and keratinizing tumours that are seen at older ages and are not related to HPV. Moreover, in these locations it is also more difficult to establish in which cases HPV is the attributable factor. In this sense, most studies accept in addition to the detection of DNA-HPV in the tumour, other transforming activity markers such as the presence of E6 or E7 mRNA or p16. Based on these data, it is estimated that the 
cases attributable to HPV are approximately $88 \%$ of anal cancer, $51 \%$ of penile cancer, $78 \%$ of vaginal cancer, and between $15 \%$ and $48 \%$ of vulvar cancer [17].

Data on the burden of HPV-related neoplastic disease in 32 countries in Europe have recently been published for 2015. The estimated number of new cases per year for cervical cancer is 34,939 cases, for 31 countries as a whole (assuming that HPV is causative for practically $100 \%$ of cases). In vulvar cancer, there are an estimated 9,776 cases (1,554 if we take into account a fraction attributable to HPV of $15.8 \%$ ). For vaginal cancer, there are an estimated 2,224 cases $(1,562$ if we have the $70.2 \%$ fraction attributable to HPV). In anal cancer, 4,663 cases $(2,801$ with a fraction attributable to HPV of $87.1 \%)$. Finally, for penile cancer, 4,231 cases $(1,227$ cases with a fraction attributable to HPV of 20.9\%) [34].

Although anogenital premalignant lesions are much more frequent than cancer, their lack of recording makes it very difficult to estimate their prevalence. A recent analysis provides data on Europe for 2015. It is estimated that between 263,227 and 503,010 cases of grade $2+$ cervical intraepithelial neoplasia (CIN) are diagnosed annually; 1,549 cases in women and 1,097 cases in men of grade $2 / 3$ anal intraepithelial neoplasia (AIN), between 13.997 and 27,773 cases of grade 2 and 3 vulvar intraepithelial neoplasia (VIN), and between 2,596 and 4,751 cases of grade 2 and 3 vaginal intraepithelial neoplasia (VaIN.)

High quality cancer incidence data are essential. Such information is currently only available to a small fraction of the world's population. The absence of this information may lead to a misinterpretation of the actual disease burden, as well as to a possible delay or neglect in the implementation of preventive measures or an impossibility to evaluate such measures.

\section{Conclusion}

The neoplastic and pre-neoplastic disease burden related to HPV is very high, affecting women in particular.

In Europe, although most countries have cervical cancer screening programmes, HPV-related neoplasms account for more than 53,000 cases annually and precancerous lesions for approximately $680,000-844,000$ cases.

HPV-related cancers, despite the availability of multiple preventive strategies, remain a major cause of morbidity and mortality in many parts of the world, particularly in less developed countries. A very high fraction of these neoplasms are preventable by screening and detection of precursor lesions and with the currently available vaccines.

\section{QUESTION: WHAT WOULD BE THE IMPACT OF HPV AS A CAUSAL AGENT OF EXTRAGENITAL TUMOURS?}

Beyond anogenital locations, HPV is associated with head and neck cancer The term "head and neck cancer" has been widely adopted in recent literature to include lesions at several anatomical sites: the lip, oral cavity, nose and sinuses, nasopharynx, oropharynx, hypopharynx, and larynx[35]. HPV is predominantly associated with oropharyngeal cancer and within that with tonsil cancer.

The classic risk factors for head and neck cancer are tobacco and alcohol use, but recent decades have seen an increase in the proportion of HPV-associated oropharyngeal cancer cases. This increase may be due to changes in sexual behaviour as well as a decrease in the prevalence of smoking.

Annually, 24,000 new cases of HPV-associated oropharyngeal cancer are diagnosed in men and 5,500 in women [32]. Globally, the proportion of HPV-associated cases in oropharyngeal cancer is 30\% (and of the tonsil about 50\%) with a large difference depending on countries-regions, being more than $80 \%$ in countries such as the USA or Northern Europe, and less than $10 \%$ in countries in Africa or other regions $[16,19]$. HPV 16 is the most prevalent type found in more than $80 \%$ of HPV-positive tumours. It should be noted that HPV-related oropharyngeal cancers differ from unrelated cancers in both epidemiological and clinical and molecular characteristics. Patients with positive HPV16 tumours appear to have better overall and disease-specific survival compared to the negative group. Laryngeal squamous cell papilloma and recurrent respiratory papillomatosis are well established HPV-induced tumours, primarily 6 and 11 .

\section{Conclusion}

HPV causes a high proportion of head and neck cancers, particularly those of the oropharynx and within the oropharynx especially those of the tonsil.

\section{QUESTION: IS IT POSSIBLE TO MEASURE THE IMPACT OF THE HEPATITIS B AND C VIRUSES ON THE INCIDENCE OF LIVER TUMOURS?}

Within the natural history of chronic hepatitis of viral origin, the chronic hepatitis-cirrhosis-cancer sequence has been well known for decades. This incontrovertible data allows us to pose different questions of great relevance, such as whether it is possible to know the epidemiological impact of this association.

The question is not simple; unlike the unidirectional and almost linear relationship between other types of viral infection and the development of cancer, the oncogenic capacity of hepatotropic viruses is modulated by different factors, as listed below.

\section{i) Cirrhosis is an oncogenic element "per se"}

A differential and characteristic data of hepatocellular carcinoma is that in more than $85 \%$ of cases it occurs in a liver affected by cirrhosis. Strikingly, it is common to find hepatocellular carcinoma in patients with cirrhosis of non-viral cause (such as alcoholism and particularly metabolic fatty liver disease). This fact, besides having a marked influence on 


\begin{tabular}{|c|c|c|c|c|c|c|}
\hline \multirow{3}{*}{\begin{tabular}{c|} 
Table 2 \\
Geographical region
\end{tabular}} & \multicolumn{6}{|c|}{$\begin{array}{l}\text { Incidence of hepatocellular carcinoma in different geographical areas and risk } \\
\text { factors }\end{array}$} \\
\hline & & Adjusted incidence $/ 100,000$ inhabitants & \multicolumn{4}{|c|}{ Risk factors } \\
\hline & Male & Female & HCV $(\%)$ & HBV $(\%)$ & Alcohol (\%) & Others $(\%)$ \\
\hline Europe & 6.7 & 2.3 & $60-70$ & $10-15$ & 20 & 10 \\
\hline Southern Europe & 10.5 & 3.3 & & & & \\
\hline Northern Europe & 4.1 & 1.8 & & & & \\
\hline North America & 6.8 & 2.3 & $50-60$ & 20 & 20 & 10 (NASH) \\
\hline Asia and Africa & 21.6 & 8.2 & 20 & 70 & 10 & 10 (Aflatox) \\
\hline China & 23 & 9.6 & & & & \\
\hline Japan & 20.5 & 7.8 & 70 & $10-20$ & 10 & 10 \\
\hline Africa & 1.6 & 5.3 & & & & \\
\hline Worldwide & 16 & 6 & 31 & 54 & 15 & $?$ \\
\hline
\end{tabular}

the treatment strategy, indicates that the mechanisms associated with the development of cirrhosis (inflammation, angiogenesis, fibrogenesis, etc.) generate a micro-environment with its own oncogenic potential independent of the viral infection itself.

\section{ii) Each virus has its own oncogenic potential}

Regardless of the relatively similar natural history of

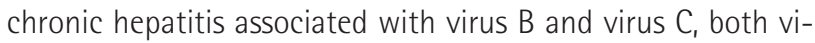
ruses are very different in terms of their own character (DNA or RNA virus), their replicative cycle (with or without integration into the host cell genome) and the different degrees of production of necrosis, oxidative stress, expression of viral proteins etc. Furthermore, the relationship between the intensity of viral replication and the risk of cancer is clearly different; while it is clear in virus $B$, it does not exist in the case of virus $C[36,37]$. Finally, the possibility of liver cancer in patients without cirrhosis is markedly more frequent in patients with hepatitis $B$, especially in Asia.

\section{iii) There are significant geographical differences}

The contribution of the different risk factors linked to the development of hepatocellular carcinoma has clear geographical differences that are related to the most frequent cause(s) of cirrhosis in each area. Thus, the incidence of hepatocellular carcinoma in Europe is mostly associated with patients with

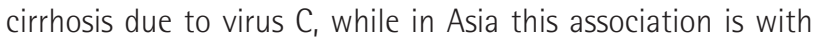
virus $B$ (Table 2).

\section{iv) Chronic viral infection is associated with other risk conditions \\ It is well known that the progression of chronic liver dis- ease is affected by different factors that are often present in patients with viral origin chronic liver disease, such as alcohol consumption, the presence of metabolic syndrome, or tobacco use. It should be noted that they are all well-known co-factors involved in the development of cancer. Therefore, the precise}

contribution of each of the factors involved (viral and non-viral) in the development of liver neoplasms is difficult to define [38].

In any case, there is no doubt that both by direct and indirect mechanisms (through the presence of cirrhosis, as mentioned above) the association between hepatotropic viruses and liver cancer is of unquestionable relevance, being possibly responsible for more than 60\% of primary liver tumours.

\section{Conclusion}

Hepatitis B and C viruses have an undisputed oncogenic power, but their relative role is difficult to ascertain when other independent oncogenic elements such as cirrhosis, fatty liver, alcohol or tobacco are factored in.

\section{QUESTION: WHAT HAVE HTLV-I AND HIV MEANT AS DIRECT OR INDIRECT CANCER-CAUSING AGENTS?}

HTLV-1 and HIV are two viruses first described in the 1980 s and directly or indirectly involved in human oncogenesis. Both share the same transmission routes (breast milk, sexual relations, blood products), the integration of their genome into the T cell and a long latency period, more pronounced in the HTLV-1, between infection and disease development.

\section{Human T lymphotropic virus type 1 (HTLV-1)}

HTLV-1 infects 10-20 million people worldwide and its main geographical distribution is Japan, the Caribbean, South America and sub-Saharian Africa. Only 5\% of infected people develop disease and the 2 conditions that it causes are adult T-cell leukaemia-lymphoma (ATL) and HTLV-1-associated myelopathy or tropical spastic paraparesis [39].

People with HTLV-1 positive serology have a 2-5\% risk of 


\begin{tabular}{|c|c|c|c|c|c|}
\hline Table 3 & himoyama Classifi & ation $[41,42]$ & & & \\
\hline Subtype & Affectation & Leukaemia cells & Hypercalcaemia & LDH & Survival \\
\hline \multirow[t]{3}{*}{ Acute leukaemia (60\%) } & Lymphadenopathy & Yes & Yes & Elevated & 6 months \\
\hline & Extranodal & & & & \\
\hline & Visceromegalies & & & & \\
\hline \multirow[t]{3}{*}{ Lymphoma (20\%) } & Lymphadenopathy & № $(<1 \%)$ & Yes & Elevated & 10 months \\
\hline & Extranodal & & & & \\
\hline & Visceromegalies & & & & \\
\hline Chronicle (15\%) & $\begin{array}{l}\text { Skin, liver, spleen, lung, } \\
\text { lymphadenopathy }\end{array}$ & Occasionally & No & $<2.5$ & 24 months \\
\hline Indolent (5\%) & Skin, lung & Occasionally (>5\%) & No & $<1.5$ & Years \\
\hline
\end{tabular}

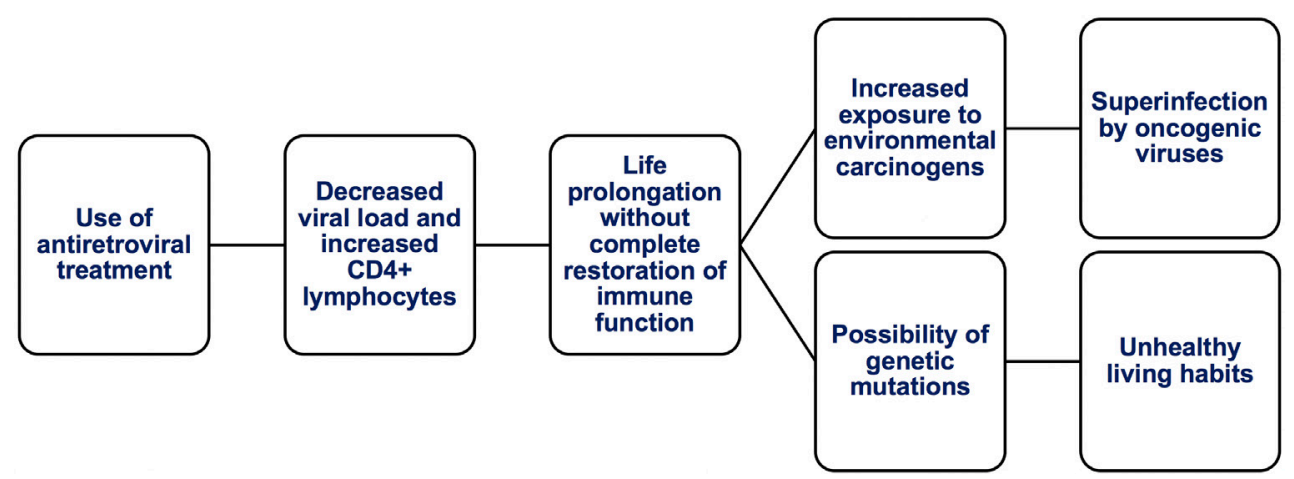

\begin{tabular}{l|l} 
Figure 1 & Effects of ART on the immunity that condition the appearance of
\end{tabular} neoplasms in HIV+ patients under treatment.

developing ATL over their lifetime. The risk is greater in males and typically appears 4-5 decades after infection in subjects who acquire it in childhood, with rare occurrence in those who become infected in adulthood [40].

The HTLV-1 genome is composed of a single strand of RNA that is integrated into the cell. It then expresses 2 oncogenic proteins: the transcriptional transactivator protein (Tax) and the HBZ protein. Both proteins, Tax and HBZ, are specifically and directly involved in oncogenesis with Tax being the initiator of tumour genesis and HBZ being in charge of maintenance [40].

ATL is characterised by a clonal proliferation of CD4+ T cells with the HTLV-1 integrated. These cells, morphologically, have a dentate nucleus with dense chromatin and basophilic (flower-like) cytoplasm. There are 4 clinical forms, the characteristics if which are summarised in Table 3. Treatment is not very effective in any of the stages and, although in aggressive cases there is an initial response with chemotherapy, early relapses with fatal outcomes occur in short periods of time. The combination of AZT with interferon has been used in some patients with variable results.

\section{Human Immunodeficiency Virus (HIV)}

The origin of tumour diseases in patients with HIV infection is multifactorial, the most important factors being HIV itself, immunosuppression, co-infection with oncogenic viruses and increased survival due to the use of antiretroviral treatment (ART) (Figure 1). HIV is a necessary but not sufficient condition, as it is not strictly considered an oncogenic virus. However, fragments of its genome have been found in some patients with $\mathrm{NHL}$, and the tat gene appears to be involved in the growth of Kaposi's sarcoma cells. For all these reasons, it is considered an essential agent, but not the only one for the development of the tumours that appear in these patients [43].

Immunosuppression and uncontrolled HIV viremia increase the risk of developing neoplasms, such that an undetectable viral load and CD4+ lymphocytes $>500$ per $\mathrm{mm}^{3}$ are factors that protect against the development of some tumours, which explains why a decrease in the number of AIDS-defining malignancies (ADM) has been observed with the use of ART. On the other hand, paradoxically, there is an increase in non-AIDS-defining malignancies (NADM) due, 


\begin{tabular}{|c|c|c|}
\hline \multirow[t]{2}{*}{ Table 4} & \multicolumn{2}{|c|}{ Differences and similarities between HTLV-1 and HIV } \\
\hline & HTLV-1 & HIV \\
\hline Classification & Retrovirus & Retrovirus \\
\hline Target cell & CD4+ lymphocytes & CD4+ lymphocytes \\
\hline Mechanism of action & T-cell proliferation and transformation & T-cell death \\
\hline Genome integration & Yes & Yes \\
\hline \multirow[t]{3}{*}{ Routes of infection } & Sexual & Sexual \\
\hline & Breastfeeding & Breastfeeding \\
\hline & Transfusion & Transfusion \\
\hline Latency & Yes & Yes \\
\hline Oncogenesis & Direct & Indirect \\
\hline Associated Neoplasm & Adult T-cell leukaemia-lymphoma & Relationship with ADM and NADM \\
\hline
\end{tabular}

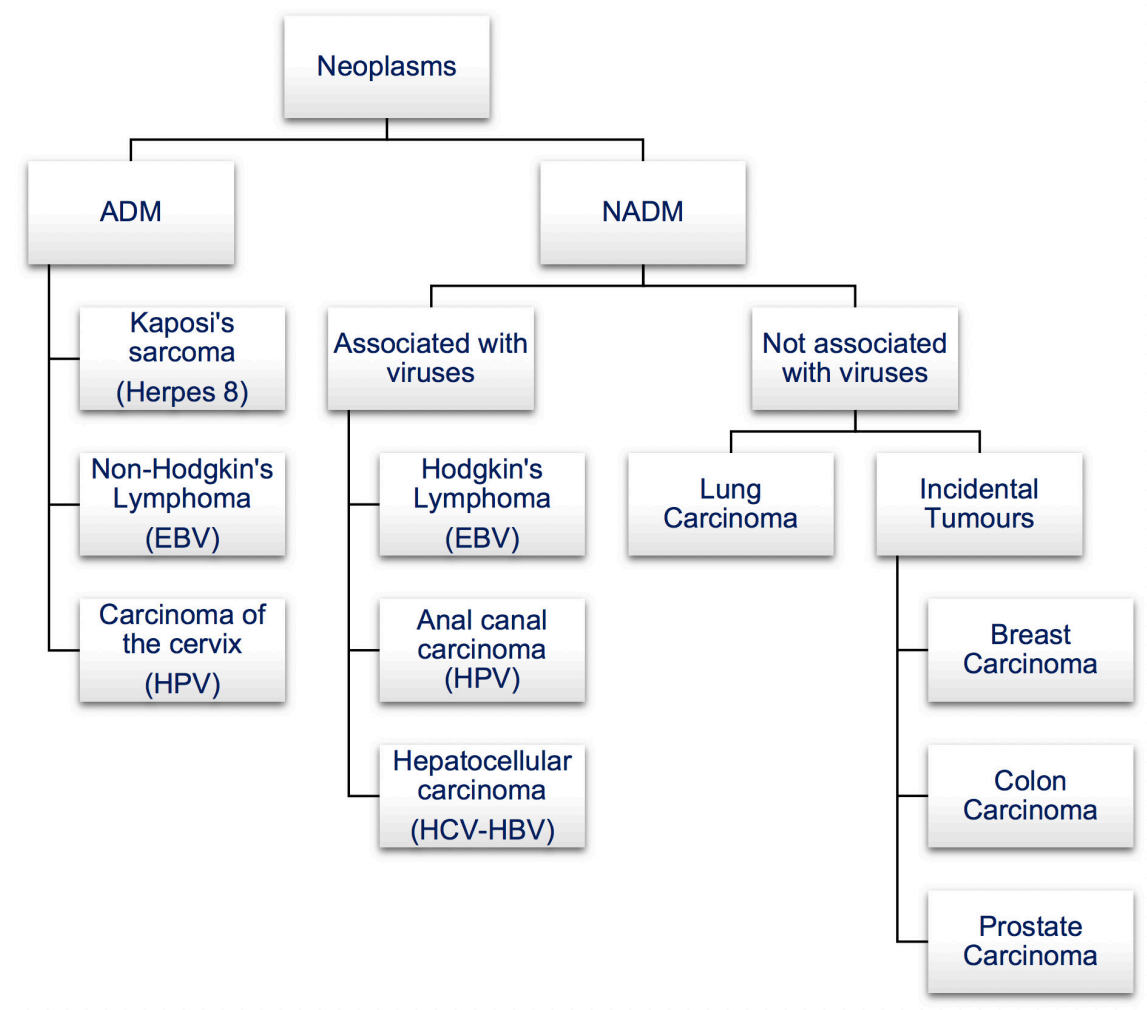

Figure 2 Classification of the tumours that appear in HIV+ patients.

in part, to the increased survival of patients as a result of the use of ART, which prolongs life without completely restoring immune function (Figure 2). All of this conditions a greater exposure to environmental carcinogens (tobacco, ultraviolet light), a greater possibility of superinfection by oncogenic viruses and an increase in the possibilities of genetic mutations appearing in patients with a family history of cancer, giving rise to the appearance of neoplasms that 
in other times did not develop due to the early mortality of the patients (Figure 1) $[43,44]$.

Another important point is that the presence of HIV causes a persistent stimulation of B lymphocytes, which alters anti-tumour immunity, facilitates the expression of oncogenic genes and allows superinfection by viruses with oncogenic capacity, such as EBV, HVH-8, HBV, HCV or HPV. All ADM are associated with viral diseases, as well as the most frequent ones within NADM except for pulmonary carcinoma directly related to smoking (Figure 2) [44]

Table 4 shows the differences and similarities between HTLV-1 and HIV.

\section{Conclusion}

Both viruses, HTLV-I and HIV share the transmission routes, infect CD4+ T-lymphocytes and are involved in human oncogenesis. The HTLV-I in a direct way, originating the T cell Leukaemia-Lymphoma and HIV, favouring the appearance of Tumours, both AIDS defining and non-defining.

\section{QUESTION: WHAT PROPORTION OF HIV PATIENTS WHO DIE DO SO BECAUSE OF AN HIV- ASSOCIATED NEOPLASM?}

Since the introduction of ART in 1996, mortality among people living with HIV (PLHIV) has decreased significantly (Figure 3) so that in 2016, 498 people died while in the initial years of the epidemic the numbers were much higher, reaching 5,857 deaths in 1995. However, immune reconstitution is generally not complete, so patients are exposed to the effects of chronic inflammation and persistent immune activation. Both processes favour the appearance of the so-called nonAIDS diseases, whose importance has progressively increased in recent years and which are one of the main causes of morbidity and mortality among PLHIV. This broad group of diseases includes most comorbidities, which in some cases become more important than the HIV infection itself. Among other processes, cardiovascular pathology, renal disease, osteoporosis and bone fractures, neurocognitive impairment and tumour pathology stand out.

Malignant neoplasms are a major cause of hospitalisation and death in PLHIV as a result of ART use and a decrease in opportunistic infections. Today, cancer can be diagnosed in $25-40 \%$ of patients, and while in the pre-ART era only $10 \%$ of deaths were of tumour origin, now up to $30 \%$ are. In our environment, according to data from the CORIS cohort, neoplasms were the most frequent cause of death by non-AIDS diseases between 2004 and 2015. In this same study it is important to note that $38.2 \%$ of the tumours diagnosed were AIDS-defining malignancies (ADM) and 61.8\% were non-AIDS-defining malignancies (NADM) (Table 5) [45].

At the EACS Congress, the results obtained from the review of neoplasms diagnosed from 1986 to 2018 in a Spanish centre were communicated [46]. 643 out of 5,411 patients $(12 \%)$ suffered at least one neoplasm. NADM increased over time with a decrease in the ADM/NADM ratio (Figure 4). 101 patients (15.9\%) died due to tumour progression, with higher mortality among NADM $25.3 \%$ vs. ADM $10.6 \%$ ( $p<0.001)$. The highest mortality was seen in tumours of the pancreas (90\%), lung (68\%) and colon (69\%).

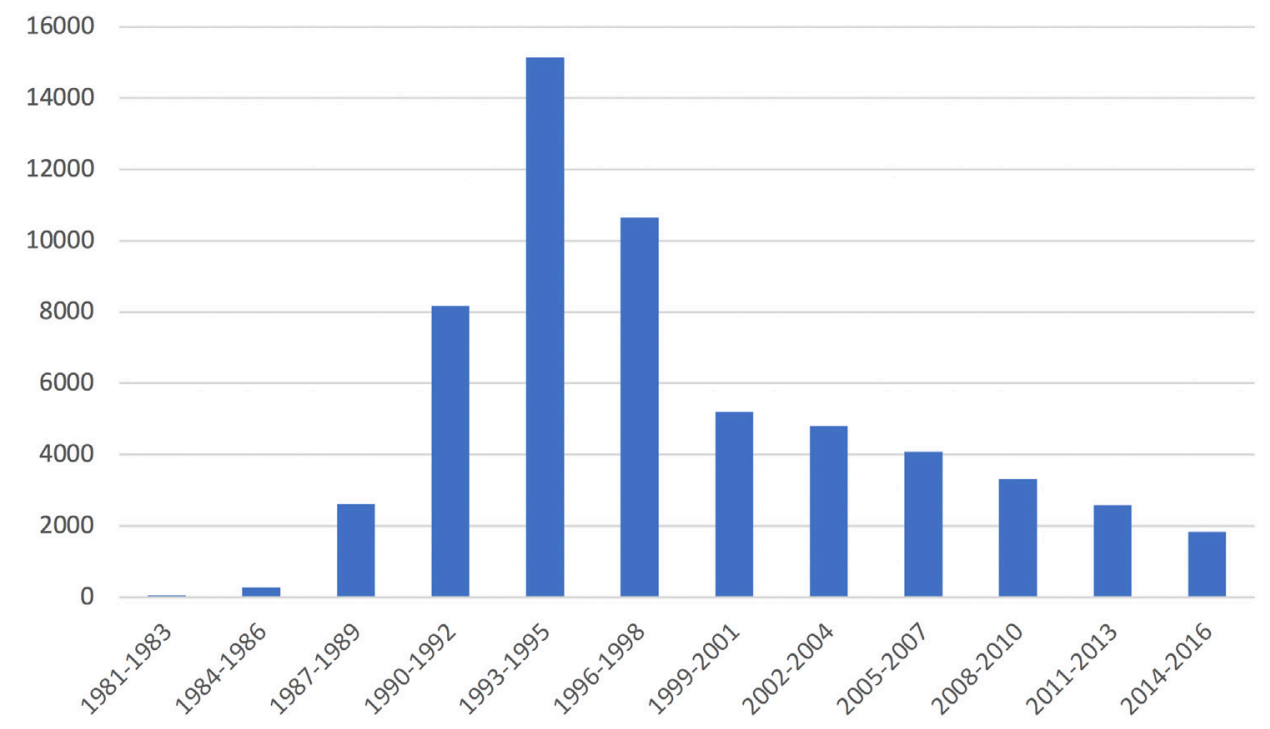

Figure 3 Evolution of mortality in people living with HIV in Spain from 1991 to 2016 (data taken from the National Institute of Statistics) 


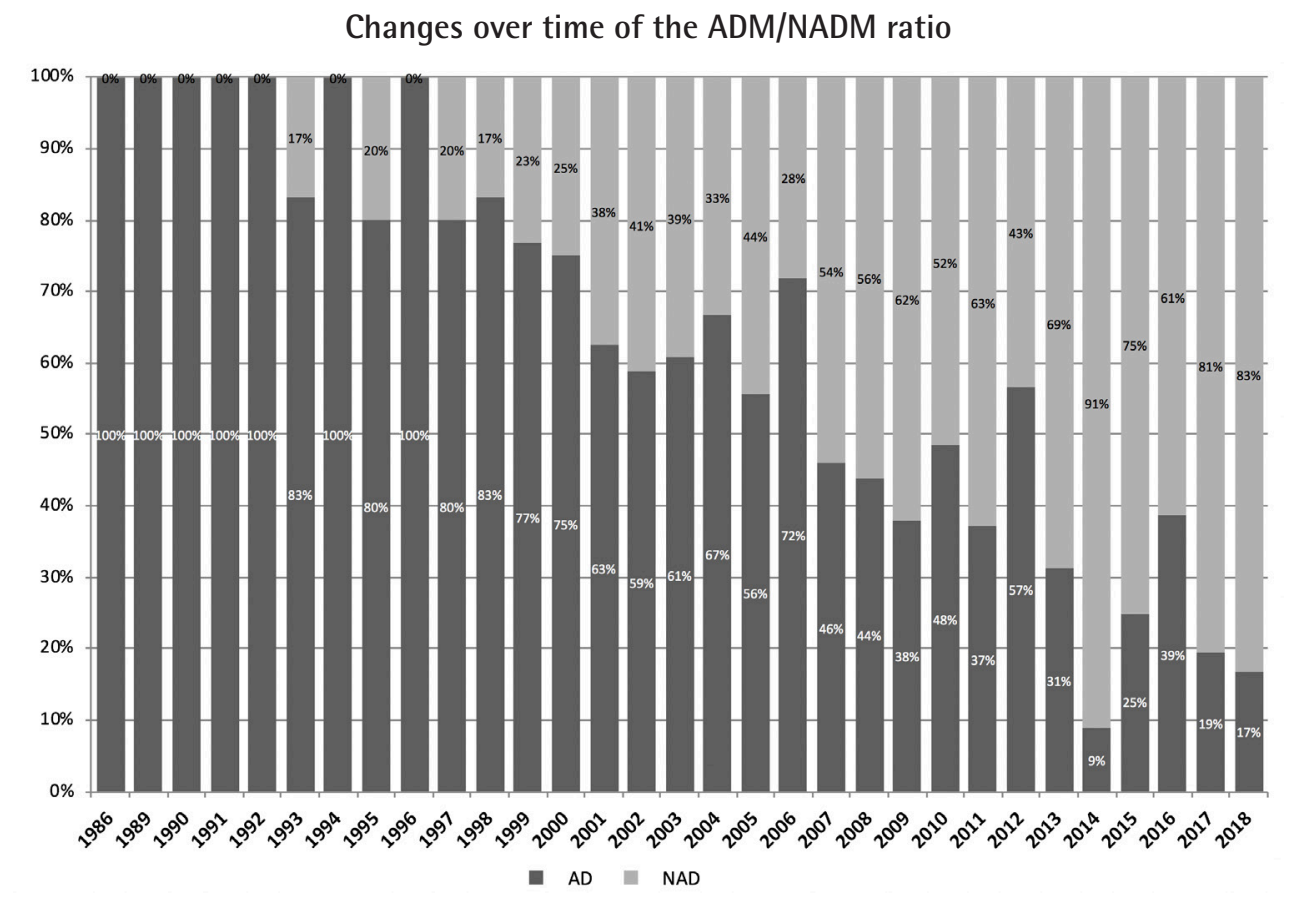

Figure 4 Changes observed over time in the AIDS-defining malignancies (ADM) / non-AIDS-defining malignancies (NADM) ratio

\begin{tabular}{|c|c|c|c|}
\hline Table 5 & \multicolumn{3}{|c|}{ Mortality of tumour origin in different series of people living with HIV } \\
\hline Author & Study & Years & Results \\
\hline Gotti et al [49] & Analysis of survival & $1998-2012$ & $\begin{array}{l}866 \text { tumours were diagnosed in } 13,388 \text { patients: } \\
-435 \text { ADM }(51 \%) \\
\text { - } 431 \text { NADM }(49 \%) \\
40 \% \text { deaths due to tumour at the end of the analysis }\end{array}$ \\
\hline Trepka et al [50] & Mortality & $2000-2014$ & $\begin{array}{l}\text { Monitoring of } 89,171 \text { PLHIV } \\
\text { Died due to cancer } \\
\text { - } 419 \text { females }(8.2 \%) \\
-1,062 \text { males }(9.1 \%)\end{array}$ \\
\hline Cevallos et al [51] & Mortality & $2007-2014$ & $\begin{array}{l}\text { 1,999 patients died (11.7\%) } \\
\text { - } 336 \text { due to NADM (16.8\%) } \\
\text { - } 115 \text { due to ADM (5.8\%) }\end{array}$ \\
\hline Croxford et al [52] & Mortality & 2016 & $\begin{array}{l}\text { There were } 206 \text { deaths among } 38,700 \text { patients } \\
\text { NADM resulted in } 40 \text { deaths }(19.4 \%)\end{array}$ \\
\hline
\end{tabular}

Another Spanish group [47] analysed the mortality in 157 PLHIV and found that 56 deaths were directly related to AIDS and 13 of them (23.2\%) were due to a ADM. In the same series another 86 deaths occurred due to non-AIDS related processes and $14(16.4 \%)$ were as a result of a NADM. Therefore, the overall mortality due to a neoplasm in this series was $17 \%$.
In other series outside our scope, the results are similar. Thus, Engels et al [48] found that approximately 10\% of deaths in PLHIV receiving ART during the period 1995 to 2009 were due to a neoplasm with a progressive increase over time. A large proportion of the deaths were due to non-Hodgkin's lymphomas, lung cancer and hepatocellular carcinoma. As in our environment, it is observed that deaths due to NADM are 
increasing in importance while there is a decrease in the number of deaths due to AIDS itself.

All these studies show a decrease in mortality from AIDS-indicating diseases and a predominance of deaths from non-AIDS diseases in recent years, with neoplasms being one of the most frequent causes in all the series, even though the patients are on ART and virologically suppressed.

In Table 1 we see reflected the importance of death of tumour origin in PLHIV in other series different from those described in the text

Conclusion

Non-AIDS defining malignancies are one of the most frequent causes of death in HIV-infected patients despite the fact that the sick receive effective antiretroviral treatment.

\section{QUESTION: WHAT IS THE INVOLVEMENT OF HERPESVIRUS IN THE CAUSALITY OF CANCER?}

The human herpes virus (HHV) group includes herpes simplex virus (HSV) 1 and 2, varicella zoster virus (VZV), cytomegalovirus (CMV), Epstein Barr Virus (EBV), HHV-6, 7 and 8. In general, they are characterised by producing primary infection at an early age and subsequently establishing latency in different tissues, from which they are able to reactivate, producing clinical manifestations again. In Table 6 we have summarised their most frequent clinical manifestations, including the tumour processes with which they have been associated.

Involvement in tumour processes is well established for EBV and HHV-8, and we will devote most of our review to them [53-55]. The rest of the herpes viruses are not considered to directly cause any type of cancer, although their role as co-factors is discussed. For example, there is some evidence to suggest that HSV-2 may increase the risk of cervical cancer after HPV infection and that it may play a role in the tumour genesis of serous ovarian carcinoma and in some prostate tumours [56]. Associations between HHV6 and different tumours have also been sought, but these have not yet been confirmed.

We will focus on the involvement of EBV in the development of tumour processes. EBV is the primary agent of infectious mononucleosis. It establishes latency asymptomatically in virtually all adults, in B cells, T cells, epithelial cells and myocytes and usually does not cause a cytopathic effect. However, it shows a clear ability to transform cells and is associated with the development of B-cell lymphomas, T-cell lymphomas, Hodgkin's lymphomas and nasopharyngeal and other head and neck carcinomas [57]. In transplant recipients, it produces a Post-transplant lymphoproliferative disease (PTLD) that can be very aggressive [58].

- Burkitt's lymphoma (BL), is the most common childhood malignancy in equatorial Africa (8-10 cases/105 annually) [57] and characteristically affects the jaw. The relationship between $B L$ and EBV is practically 100\% in endemic cases, 10-80\% in sporadic cases and 30-40\% in HIV-related cases. The cells usu- ally express EBNA and CD20. It is considered that malaria may also be a co-factor in the production of this tumour, although the mechanism is not clear (immunosuppression of specific $T$ cells, increased EBV viral load, or favouring reactivation of the virus in B lymphocytes, among other theories).

- Nasopharyngeal carcinoma is a rare tumour in most parts of the world, except in southern China, where it is one of the most common cancers [59]. Unlike Burkitt's lymphoma, EBV is present in all anaplastic nasopharyngeal carcinoma cells, in both high- and low-incidence areas [60]. However, other co-factors are necessary (exposure to environmental carcinogens in food, genetic alterations, etc.), since the seroprevalence of EBV infection is much higher than the incidence of the tumour. Nasopharyngeal carcinoma cells express dormant proteins of EBV, including EBNA-1 and two membrane proteins, LMP-1 and LMP-2, along with the BamHI-A fragment of the EBV genome.

- HIV+ patients have a lymphoma incidence 60-100 times higher than expected and $70 \%$ of them are associated to EBV infection, usually of monoclonal origin. The profound immunosuppression of these patients facilitates the failure of EBV control by decreasing specific cytotoxic lymphocytes. Non-Hodgkin's lymphomas in HIV+ patients often affect the CNS. In B-cell lymphomas, EBV-coded proteins promote cell immortalisation and proliferation by stimulating the NF- $\kappa B$ pathway and increasing the expression of anti-apoptotic genes. In HIV+ children, EBV infection has been linked to the development of smooth muscle tumours (leiomyoma and leiomyosarcoma). The non-Hodgkin's lymphoma most frequently associated with EBV is diffuse large cell.

- As early as the 1980s it was shown that the EBV genome is found in more than $50 \%$ of Hodgkin's lymphomas, including Reed-Sternberg cells [61]. It is also demonstrated in patients with $\mathrm{HL}$-induced hemophagocytic syndrome. The proportion of $\mathrm{HL}$ with EBV is even higher in children under 10. The two most frequent markers in $\mathrm{HL}$ are EBER-1 and the latent membrane protein (LMP) [53].

- $\quad$ EBV infection is also associated with T-cell lymphomas, including fulminant forms of T-cell lymphoma after acute EBV infection. In the context of mature T/NK Iymphomas, with the possible exception of extranodal NK/T cell lymphoma, the role played by EBV infection is even more complex than in B lymphomas and exceeds the intention of this review. It has been proposed that the type of infected cell, the EBV viral load in plasma, and the degree of viral lymphatic replication have prognostic value in T/NK cell lymphomas.

- Another lymphoma associated with EBV infection is nasal angiocentric lymphoma, which is endemic in Asia, Central and South America. This tumour affects the nasal septum, palate, gastrointestinal tract and, less frequently, the skin, testicles and peripheral nerves. EBV is detected in virtually all neoplastic cells that are probably derived from NK cells [62].

- $\quad$ PTLD is associated in most cases with EBV. The term includes a continuum of abnormalities ranging from benign polyclonal B-cell proliferation to malignant B-cell lymphoma. In these disorders the virus directly induces the transformation of naive or mature mem- 


\begin{tabular}{|c|c|c|}
\hline Table 6 & \multicolumn{2}{|c|}{$\begin{array}{l}\text { Taxonomy of Human Herpes Viruses and the diseases } \\
\text { they cause }\end{array}$} \\
\hline Subfamily & Species & Related diseases (in bold for tumour diseases) \\
\hline \multirow[t]{5}{*}{ Alfa-herpesvirinae } & Herpes Simplex & Herpes labialis \\
\hline & HSV-Type 1 & Herpetic stomatitis, encephalitis \\
\hline & HSV-Type 2 & Genital herpes, encephalitis \\
\hline & Varicella-Zoster & Chickenpox \\
\hline & & Herpes Zoster \\
\hline \multirow[t]{3}{*}{ Beta-herpesvirinae } & Cytomegalovirus & Pneumonia, hepatitis, viral syndrome, etc. \\
\hline & Herpesvirus 6 & Exanthema subitum \\
\hline & Herpesvirus 7 & \\
\hline \multirow[t]{8}{*}{ Gamma-herpesvirinae } & Epstein Barr & $\begin{array}{l}\text { Infectious mononucleosis, Burkitt's lymphoma, } \\
\text { nasopharvngeal carcinoma. Hodakin's }\end{array}$ \\
\hline & & lymphoma, PTLD, diffuse large-cell B-cell \\
\hline & & lymphoma, angioimmunoblastic T-cell \\
\hline & & lymphoma, NK nasal T-cell lymphoma, \\
\hline & & plasmablastic lymphoma,... \\
\hline & Herpesvirus 8 & Kaposi's sarcoma \\
\hline & & Castleman's disease \\
\hline & & Cavity Lymphoma \\
\hline
\end{tabular}

ory cells. The frequency of PTLD is related to post-transplant immunosuppression and is more frequent in EBV-negative recipients who develop primary infection, and therefore in transplanted children. Recovery of T-immunity or administration of specific T-cells (adoptive immunity) will bring the disease back.

- Other entities related to this virus are hemophagocytic Iymphohistiocytosis, Iymphomatoid granulomatosis or $\mathrm{X}$-linked lymphoproliferative disease.

The treatment of all these tumours does not include the administration of antivirals since the cells are not in the lytic cycle, which is necessary for Acyclovir to be effective. The usefulness of cell therapy with specific cytotoxic T-lymphocytes against EBV and Rituximab is being studied.

\section{Conclusion}

Among herpes viruses the association with the development of neoplasms is well established for EBV and HHV-8. EBV is capable of promoting tumour transformation in multiple cells and is associated, among others, with B-cell lymphomas, including Hodgkin's and non-Hodgkin's lymphomas, T-cell lymphomas, nasopharyngeal carcinomas, other head and neck carcinomas, and post-transplantation lymphoproliferative disease.

\section{QUESTION: WHAT IS THE RELATIONSHIP BETWEEN KAPOSI'S SARCOMA AND HERPES VIRUS?}

Kaposi's sarcoma (KS) is an angioproliferative tumour and one of the clearest examples of a tumour that requires infection by a virus and that is also modulated by the patient's immune status. The pathogenesis of the tumour requires infection with human herpesvirus 8 (HHV-8), also called Kaposi's sarcoma associated herpesvirus (KSHV)[63]. It is named after Moritz Kaposi, a Hungarian dermatologist who first described the entity in 1872.

Before briefly describing some of the characteristics of the KS, it should be noted that the HHV8 also causes two other tumours: cavity lymphoma or primary effusion lymphoma (PEL) and Castleman's disease. Cavity lymphoma is a B-cell non-Hodgkin's lymphoma that has a preference for the peritoneal, pleural, and pericardial spaces. Castleman's disease is also a very rare lymphoproliferative disorder that causes fever, splenomegaly, hepatomegaly, and lymphadenopathy, and can affect both HIV-negative and HIV-positive patients.

$\mathrm{KS}$ is characterised by vessel proliferation (angiogenesis), accompanied by inflammation and proliferation of spindle cells. HHV-8 infects the cells and the gene products of the virus influence both the regulation of the cell cycle and the control of apoptosis. The infection induces a disordered proliferation of cells that mostly do not express a lytic cycle, but a latent infection. In addition, the function of the tumour suppressor genes is interrupted and recognition by the host immune system is prevented, thus promoting tumour growth. By performing a PCR in the biopsy, it is possible to amplify viral DNA sequences and also to identify, using immunohistochemistry, latent viral antigen in spindle cells (membrane proteins).

Four types of $\mathrm{KS}$ are recognised depending on the type of patients affected: 1) Classic or sporadic KS, which corre- 
sponds to the form originally described by Kaposi and which is extraordinarily rare $(0.03 \%$ per year among HIV-positive males over 50 in the Mediterranean area). It usually occurs in males over 50-60 years of age and mainly affects people from the Mediterranean area (Sardinia, Sicily, etc.) or with Jewish ancestry; 2) Endemic KS prevalent in sub-Saharan Africa before the AIDS epidemic. It affects children and adults and it is believed that continuous exposure to certain types of soil facilitates the appearance of the disease; 3) iatrogenic KS, associated with the use of immunosuppressants and described mainly in solid organ transplant recipients; 4) finally, AIDS-associated KS (epidemic KS) [64]. With better control of the AIDS epidemic, incidence in the US has dropped from rates that reached 47 cases per year per million people. Since then, Kaposi's sarcoma has become less common, producing about 6 cases per million people each year. The different epidemiological and clinical aspects of these four types are summarised in Table 7.

Infection with the HHV8 virus is a necessary condition for the development of KS, but not sufficient, since other cofactors are required for its appearance, such as genetic predisposition (sporadic form), and above all immunosuppression, either iatrogenic (organ transplant) or due to HIV infection. Thus, the prevalence of seropositivity in the population is much higher than that of Kaposi's sarcoma.

The most common clinical presentation of KS, especially in the early stages of the tumour, is skin and mucosal lesions. It is characterised by the appearance of raised violet lesions that mainly affect the lower extremities, the face (especially the nose), the oral mucosa and the genitals. They may be accompanied by significant oedema, reflecting vascular obstruction by lymphadenopathy or the action of cytokines involved in the pathogenesis of the tumour. Oral lesions appear in onethird of patients and mainly affect the gums and palate and may interfere with nutrition and speech. It is important to remember that KS can also have extracutaneous manifestations, mainly in advanced stages, affecting mainly the gastrointestinal and respiratory tracts. The gastrointestinal system is now less frequently affected. Its diagnosis is difficult in the absence of concomitant skin lesions. Clinical manifestations of gastrointestinal KS include weight loss, abdominal pain, nausea and vomiting, gastrointestinal bleeding, malabsorption, intestinal obstruction, and diarrhoea. As for lung disease, it can appear with highly variable radiological findings, including nodules, single or multiple, interstitial or alveolar infiltrates, pleural effusion, adenopathy or solitary nodules. The diagnosis is based on the characteristic appearance of the lesions in endoscopy or bronchoscopy and is confirmed by biopsy.

The incidence of KS in solid organ transplant recipients is $0-5-1 \%$ and represents approximately $6 \%$ of post-transplant tumours, excluding skin cancer. This incidence is much higher than that of the general population and is justified by the chronic immunosuppression required by transplant patients. Although KS is mostly described in HIV-positive patients, primary infection after transplantation has been shown to be the most important risk factor in our environment [65]. This primary infection can be acquired through the transplanted organ, or through the administration of blood products or other routes. About half of the KS diagnosed in transplant recipients respond only by reducing immunosuppression, or by switching to Sirolimus (Rapamycin) which has anti-tumour and anti-angiogenic effects [66].

In the patient with HIV infection, KS has been described in all risk groups, although with a higher incidence among homosexual or bisexual men, in relation to a higher seropositivity rate among these patients (close to 40\%) [67]. KS rates in some studies reached 18\%-50\% 10 years after the diagnosis of HIV infection, if the CD4 figure was $<200$ cells $/ \mathrm{mm}^{3}$ [68]. However, although the rate of HHV-8 infection has not changed, early

\begin{tabular}{|c|c|c|c|c|}
\hline Table 7 & Classification of the differe & Kaposi's Sarcoma & & \\
\hline Type & Risk groups & Cutaneous involvement & Profound involvement (visceral) & Evolution \\
\hline CLASSIC (Sporadic) & $\begin{array}{l}\text { Male/Female 3:1 } \\
\text { Age }>60 \\
\text { Mediterranean, Central or Eastern } \\
\text { European or Middle Eastern origin }\end{array}$ & Distal lower limbs & Rarely & $\begin{array}{l}\text { Normally indolent } \\
\text { Rare rapidly progressive }\end{array}$ \\
\hline ENDEMIC (Africa) & $\begin{array}{l}\text { Adult males; children of both sexes. } \\
\text { Equatorial Africa }\end{array}$ & $\begin{array}{l}\text { Similar to classic } \\
\text { (sometimes more } \\
\text { aggressive, with adult } \\
\text { lymphoedema) }\end{array}$ & $\begin{array}{l}\text { Children: deep ganglia and } \\
\text { organs } \\
\text { Adults: more rare }\end{array}$ & $\begin{array}{l}\text { Indolent or locally invasive in adults } \\
\text { Aggressive in children }\end{array}$ \\
\hline $\begin{array}{l}\text { IATROGENIC } \\
\text { Immunosuppression }\end{array}$ & $\begin{array}{l}\text { Exogenous IS, SOT } \\
\text { Age }>50 \\
\text { Cyclosporin A }\end{array}$ & $\begin{array}{l}\text { Distal lower limbs or } \\
\text { scattered }\end{array}$ & Common & $\begin{array}{l}\text { May disappear on modification of IS. } \\
\text { May be aggressive }\end{array}$ \\
\hline AIDS-related & $\begin{array}{l}\text { MSM in developed countries } \\
\text { Heterosexual men and women in } \\
\text { Africa }\end{array}$ & Localised or scattered & Common if poorly controlled HIV & $\begin{array}{l}\text { Aggressive or indolent. } \\
\text { May disappear with HIV control }\end{array}$ \\
\hline
\end{tabular}

MSM: men who have sex with men; IS: immunosuppression; SOT: solid organ transplant 
and effective antiretroviral treatment has significantly reduced the frequency of this tumour. The standardised incidence rate (SIR) for Kaposi's sarcoma compared to the general population was 22,100, and declined to 3,640 with widespread use of antiretroviral treatment [69].

Some HIV+ patients with Kaposi's sarcoma present with a systemic inflammatory syndrome due to cytokine release (KICS) that is characterised by fever, gastrointestinal, respiratory and neurological manifestations and is associated with an elevated KSHV tumour load.

Treatment of KS depends on the extent of the tumour and its location and symptoms. As with solid organ transplant recipients, HIV-positive patients may respond to immune recovery from the initiation of highly active antiretroviral therapy (HAART), although others may also require local or systemic chemotherapy. It has also been observed that KS is less frequent in patients who have received Ganciclovir or Foscarnet, demonstrating the relative sensitivity of the virus to these antivirals. The relative survival over five years is over $75 \%$.

\section{Conclusion}

Kaposi's Sarcoma is a tumour that requires prior infection with Human Herpes Virus type 8 as a necessary, but not sufficient, cause. Tumour development requires associated factors that may be genetic or due to immunosuppression. It exists in four clinical versions: Classic, Endemic, latrogenic or HIV-associated Kaposi's Sarcoma.

\section{QUESTION: DO MICROORGANISMS OTHER THAN VIRUSES HAVE AN ONCOGENIC ROLE?}

Viruses are certainly the most oncogenic infectious agents. However, there are other non-viral microorganisms that are clearly related. A bacterium: Helicobacter pylori; and three parasites (the so-called "Oriental liver flukes"): Schistosoma haematobium, Clonorchis sinensis and Opisthorchis viverrini," are classified in Group I of carcinogens by the International Agency for Research on Cancer

\section{Cancer-related bacteria}

-Helicobacter pylori is a helical bacillus that lives exclusively in the human gastric epithelium. H. pylori infection can cause inflammation of the gastric mucosa that can progress, leading to gastritis, peptic ulcers and mucous-associated lymphoid tissue lymphoma (MALT). Because of its spiral shape, it can literally "screw itself in" to colonize the stomach epithelium, in addition to having the urease that allows it to neutralise its acidic environment. The bacteria generates free radicals, injects a cytotoxin known as CagA that alters the structure of the cells lining the stomach and generates locally high levels of molecules signalling inflammation such as TNF-alpha or interleukin 6 that could induce mutation of the epithelial cells of the stomach. Tropheryma whipplei, another bacteria in the digestive tract that causes Whipple's disease, may be associated in a similar way with neoplasms.
Salmonella typhi has been linked with hepatobiliary and gall bladder tumours and -Chlamydia pneumoniae and Mycobacterium tuberculosis have been linked with lung cancer.

Chronic Bacterial Osteomyelitis and hidradenitis suppurativa are associated with squamous cell carcinoma of the skin also [70-74].

\section{Cancer-related parasites}

Millions of people in the world, especially those living in the tropics, suffer from some form of parasitic disease. The oncogenic role of certain parasites has been known for many decades. Three parasites, trematode helminths, cause urinary or hepatobiliary tumours $[75,76]$ :

-Schistosoma haematobium is very prevalent in sub-Saharan Africa and is a major cause of urinary bladder carcinoma. The disease is acquired after skin contact with fresh water infected with larvae. Adults invade the urinary venous plexuses and the eggs are expelled with the urine after passing through the bladder wall, causing haematuria, fibrosis and calcifications. Granulomas form on the wall of the bladder and evolve into nodules or masses that ulcerate, degenerating into both benign and malignant tumours. In addition, bladder lesions may increase the exposure of the epithelium to carcinogenic substances. Schistosoma japonicum may be oncogenic and produce colorectal cancer [77].

-Clonorchis sinensis is very prevalent in South East Asia (China, Thailand, Korea, Vietnam, Laos and Cambodia) and Opisthorchis viverrini (also found in Russia), to a lesser extent, causes cholangiocarcinoma $[78,79]$. The disease is acquired by eating raw freshwater fish. Adults invade the bile ducts and occasionally the gallbladder and pancreatic duct, where they cause cholangitis and cholecystitis and can lead to cirrhosis. In massive and chronic infections, inflammation, scaling, metaplasia and ductal fibrosis can degenerate into cholangiocarcinoma and liver carcinoma, especially in patients exposed to carcinogenic agents such as nitrosamines. Opisthorchis felineus could perhaps be equally oncogenic.

- Other parasites may have a putative or indirect oncogenic role. The association between Plasmodium falciparum and the Epstein-Barr virus is not entirely clear in the oncogenesis of Burkitt's lymphoma in Africa. Toxoplasma gondii has been detected in some patients with intraocular lymphoma. Strongyloides stercoralis may be associated with gastric lymphoma and adenocarcinoma of the colon.

-A new form of neoplasm associated with a parasite, namely Hymenolepis nana, has been reported in 2015 in an immunosuppressed patient: the transformation of the parasite into a tumour that subsequently spreads [80]. It is the first and only known case of a person suffering from cancer originating from a parasite (the cancer cells were not human but parasitic).

But, how can a parasite cause cancer? Adult helminths are constantly moving, burrowing and laying eggs that secrete toxic proteins; the host tries to get rid of them, which induces chronic inflammation that can eventually degenerate into metaplasia. 
However, some parasites may be protective in tumour genesis, inducing apoptosis phenomena and inhibiting signals of inflammatory regulation and angiogenesis. Certain proteins excreted by Fasciola hepatica, Echinococcus granulosus, Trichinella spiralis, Toxoplasma gondii, and Trypanosoma cruzi are capable of inhibiting tumour cell growth in vitro, and may be used as anti-cancer therapy in the future.

\section{Conclusion:}

A bacterium: Helicobacter pylori; and three parasites: Schistosoma haematobium, Clonorchis sinensis and Opisthorchis viverrini, are classified in Group I of carcinogens by the International Agency for Research on Cancer. Helicobacter pylori is clearly associated with gastric cancer and mucosa-associated lymphoid tissue lymphoma (MALT).

Some parasites such as Schistosoma haematobium, Clonorchis sinensis and Opisthorchis viverrini are classified by the WHO as group 1 oncogenic agents (those of proven aetiology). Other parasites have a less defined role such as Plasmodium falciparum.

A new and exceptional human tumour disease has been described after the transformation of Hymenolepis nana into a tumour.

\section{QUESTION: COULD THE CONCEPTS OF ONCOGEN AND ONCOPROTEINS BE SUMMARISED? AND THE CONCEPT OF GENOMIC INSTABILITY?}

Studies on chicken sarcoma in the first decade of the 20th century suggested that the origin of the tumours was viral. For example, pioneering studies by Peyton Rous showed how filtering pulverized chicken sarcoma through a sieve that did not allow cells to pass, only viruses, then injecting the extract, transmitted the sarcoma to the recipient chicken. Throughout almost two thirds of the century this viral theory of the origin of cancer was the main driving force behind cancer research and, in fact, a good number of viruses capable of triggering tumour processes were found. As oncologist Ludwik Gross said in 1970, "The viral origin of most malignant tumours has already been documented beyond any reasonable doubt. It would be quite difficult to assume a fundamentally different aetiology for human tumours"[81]. However, some observations did not fit with this model. For example, trying to explain the high incidence of tumours among miners, the Japanese pathologist Katsaburo Yamagiwa [82] observed that repeated exposure of the skin to charcoal induced sarcomas in rabbits. This suggested that the carbon must have some chemical agent that induced a change in the animal's skin cells, and made them grow out of control, but how?

The answer finally came in the 1980s with the discovery of oncogenes. The concept of oncogenes derives from the presence of genes that are mutated in tumour cells, and which are responsible for transforming them into malignant ones.
These genes perform normal functions in the cell such as stimulating growth, increasing survival, or defining identity. However, the presence of certain mutations in them means that, once translated into protein, they have an altered capacity capable of transforming a normal cell into a malignant one. The genes that, once mutated, give rise to oncogenes are called proto-oncogenes, and the proteins that are generated from these are called oncoproteins. The discovery of the first oncogene was published in 1982 by 3 independent laboratories, those directed by the doctors Robert Weinberg, Michael Wigler and the Spaniard Mariano Barbacid, [83] who managed to sequence transforming oncogenes isolated from bladder cancer cells [84].

The first oncogene discovered was RAS, which we know today is a family of genes whose function is to regulate cell growth in response to growth factors. Many others were later discovered, notable cases such as MYC or cyclin E (CCNE) which, as in the case of $S A R$, control cell growth. We now know that many of the oncogenes are related to genes that control cell growth in such a way that oncogenic mutations promote the uncontrolled proliferation characteristic of tumours. While for several decades it was thought that most oncogenes were related to cell proliferation or their increased survival, tumour genome sequencing studies revealed, not without surprise, that in fact the class of genes most represented among oncogenes are those related to chromatin and epigenetics. Although in many cases we still do not fully understand how these alterations in epigenetic-related genes can trigger tumour processes, the most accepted idea is that these mutations change the identity of cells and generate undifferentiated states. This undifferentiated cell, which has lost its identity, is the one that subsequently -and thanks also to other mutations that promote its growth- gives rise to tumours. As expected, oncogenic mutations are often targets of tumour treatments, and the development of drugs that target all types of oncogenes, including those epigenetic-related genes, is currently a very active field within drug development and new anti-tumour therapies.

In addition to the presence of oncogenes, another characteristic present in practically all tumour cells is genomic instability. First described by Teodor Boveri at the beginning of the 20th century [85], genomic instability is defined as the presence of genomes with multiple chromosomal aberrations in tumour cells such as: the gain or loss of entire chromosomes, chromosomal translocations, or the loss or duplication of regions of one or more chromosomes. Genomic instability is caused by failures in DNA replication [86] or in the distribution of chromosomes during mitosis, processes that are often involved in tumour cells. Furthermore, it has recently been discovered that oncogenes are also a source of genomic instability, as they promote abnormal replication that leads to DNA damage. Fortunately, all cells have mechanisms that suppress genomic instability and normal cells keep their genome stable. The fact that genomic instability is a distinctive feature of tumour cells has opened the door to anti-tumour strategies based on selectively killing cells with genomic instability. One 
known example is the poly(ADP)-ribose polymerase (PARP) inhibitors that have been shown to be effective in killing tumour cells with deficiencies in DNA repair in breast, ovarian and prostate tumours [87]. Another alternative that is now being clinically studied, and in which the laboratory of one of us played an important role, is that of ATR kinase inhibitors, which are mainly responsible for the type of genomic instability initiated by oncogenes [88].

\section{Conclusion}

Both the presence of oncogenes and genomic instability are features of tumour cells that distinguish them from normal cells, and thus they are being exploited for the development of therapies capable of selectively killing cancer cells.

\section{QUESTION: WHAT PROPORTION OF CANCER DEATHS CAUSED BY VIRUSES COULD BE PREVENTED BY EXISTING VACCINES?}

Cancer mortality series offer an uneven picture between regions of the world, due to the multiplicity of factors involved in their genesis. A global approach estimates that about 1.5 million cancer deaths could be avoided annually if the underlying infections that led to the development of the tumour were prevented or treated $[17,22,89]$.

A pioneering contribution in this area is that of Catherine de Martel et al [89] who published their analysis of the incidence of 27 types of cancer in 184 countries in Lancet Oncology in 2012, describing the fact that two thirds of these deaths occur in less developed countries. These authors carried out an analysis to estimate the proportion of cancers globally that could be attributed to infections and have calculated, by categorising the planet into eight regions, the population that could be affected by new tumours and which could have been prevented by a specific intervention against exposure. They point out that of the 12.7 million new cancers worldwide in 2008, about 2 million were attributable to infections, and of these, 1.6 million (80\%) were in developing countries. Of the 7.5 million deaths that occurred in 2008 attributable to an oncological process, an estimated 1.5 million were due to potentially preventable and treatable infections. An upwardly weighted estimate of 172 deaths worldwide could be prevented every hour from tumours caused by infectious agents potentially preventable by immunisation.

There are significant contrasts between different areas of the planet in how these infections are responsible for oncogenesis. Thus, in Australia and New Zealand the infectious origin of a cancer is identified in $3.3 \%$ of cases compared to $32.7 \%$ in Sub-Saharan Africa. In women, cervical cancer accounted for approximately half of the cancer burden related to infection; in men, liver and gastric cancers accounted for more than 80\%. About 30\% of cases attributable to infections occur in people under 50. In a smaller scope, a Spanish group has been able to describe, in a series of 190,203 cervical smears collected between 2012 and 2014, in women screened for Human Papillomavirus (HPV) in Castilla y León, that its prevalence in foreign women was $23.51 \%$, significantly higher than in Spanish women $(9.6 \% ; p<0,001)$ and that the presence of morphological changes in the foreign women was also higher [90].

The application of preventive public health methods which already exist, such as vaccines (or anti-infective treatments in another conceptual framework), could have a significant effect on the global burden of cancer in the future. In the specific field of viral agents, it is worth noting that we already have vaccines with proven effectiveness against HPV and Hepatitis B Virus (HBV) [91,92]. "Increasing vaccine coverage should be a priority for health systems in high-burden countries," as G Danaei [93] states in an editorial accompanying the aforementioned study [89].

A significant proportion of cancer cases attributable to infections can be prevented through improvements in vaccination and screening programmes. Expansion of vaccination (for HBV and HPV), screening and treatment programmes (e.g., for Hepatitis C Virus -HCV-) could greatly reduce mortality due to them.

An additional aspect of vaccination programmes is to describe their acceptance by the population, to carry out economic assessment studies that verify their suitability and availability from the perspective of the social funder, and to establish their accessibility.

In developed countries, in the context of patients co-infected with the Human Immunodeficiency Virus (HIV), very suggestive lines of work have been established by De Martel and Plummer's own group [94]. These authors indicate that, although HPV and hepatotropic viruses such as HBV and HCV do not represent a differentiated weight in this category of patients in the USA, they do constitute the Human Herpesrvirus-8 (HHV-8) at the expense of its aetiological involvement in Kaposi's Sarcoma and Epstein-Barr Virus (EBV) due to its causal relationship with lymphoid pathology. There is no doubt that the research applied to vaccines that can be extended to the Herpesviridae family will represent a decisive impulse towards minimising their impact on patients co-infected with HIV.

\section{Conclusion}

Cancer mortality series offer an uneven picture between regions of the world, due to the multiplicity of factors involved in their genesis. From a global perspective, at a low estimate, around one and a half million deaths from cancer (of which two thirds occur in underdeveloped countries) could be avoided each year if the underlying infections that led to tumour development were prevented or treated. 


\section{QUESTION: WHAT IMPACT IN NUMBERS HAS HPV VACCINATION HAD ON REDUCING FEMALE GENITAL CANCER?}

Vaccines against human papillomavirus (HPV) induce an elevated production of antibodies capable of neutralising the virus and preventing infection of the anogenital tract and, therefore, the possible development of precancerous lesions and cancer. Given the natural history of infection, which requires years or decades from initiation to development of cancer, protection against persistent infection and pre-malignant lesions is considered a surrogate marker of protection against cancer.

More than 10 years after the commercialisation of HPV vaccines, many studies provide data on their effectiveness (effectiveness in the general population and in real life) [95-99]. The fact that there is a reduction in the prevalence of vaccine genotypes or a reduction in the rate of pre-malignant lesions in the vaccinated population is certainly indicative of protection against cancer.

A recent systematic review and meta-analysis assesses the population-level impact of vaccine effectiveness in the real-world setting. Since 2007, a total of 99 countries and territories have initiated vaccination programmes. In 2016, WHO expanded the recommendation in favour of promoting the vaccination of multiple cohorts of girls over single-cohort vaccination. The analysis of 1,702 potential articles allowed the final inclusion of 65 articles carried out in 14 high-income countries (23 articles to assess HPV infection, 29 for anogenital warts and 13 for CIN2+ lesions). This meta-analysis of over 60 million individuals and 8 years of post-vaccination follow-up provides compelling evidence of the substantial impact of vaccination programmes on reducing HPV infection, and the diagnosis of anogenital warts and CIN2+ lesions [100].

Specifically, the prevalence of HPV 16 and 18 decreased significantly by $83 \%$ (RR $0-17,95 \% \mathrm{Cl} 0 \cdot 11-0 \cdot 25)$ among girls aged 13-19, and 66\% (RR 0-34, 95\% Cl 0.23-0.49) among women aged 20-24. Also, the prevalence of HPV 31, 33 and 45 decreased significantly by $54 \%$ (RR $0-46,95 \%$ Cl $0.33-0.66$ ) among girls aged $13-19$ years. Five to nine years after vaccination, diagnosis of CIN2+ lesions decreased significantly by $51 \%$ (RR $0-49,95 \% \mathrm{Cl} 0 \cdot 42-0 \cdot 58)$ among girls aged $15-19$ years and by $31 \%$ (RR 0.69, 95\% Cl 0.57-0.84) among women aged 20-24 years.

This meta-analysis demonstrates a stronger and faster direct impact, as well as a herd effect, in countries with high coverage and which included multiple vaccine cohorts. Therefore, these real-world data confirm that both the cause (highrisk HPV infection) and the immediate pre-cancer condition (CIN2+) are decreasing significantly among vaccinated populations and therefore the vaccine is effective in preventing cervical and other HPV-related cancers [100].

Another recent study in the U.S. assessed the type of HPV present in cytology samples from women aged 20-29 years assessed at Kaiser Permanente Northwest in 2007 and in two periods of the vaccine era: 2012-2013 and 2015-2016. The prevalence of vaccine HPV types went from 13.1\% in 2007 to 2.9\% in 2015-2016. After 9-10 years from the introduction of the vaccine, the prevalence of HPV vaccine types decreased by $78 \%$ among $20-24$ years old and by 38\% among $25-29$ years old. This decrease was observed in both vaccinated and unvaccinated women, which is evidence of both direct and herd protection [101].

In the same vein, data from Scotland from nine cohorts of women aged 20 years have been published to evaluate the effectiveness of the bivalent vaccine in preventing precancerous lesions. The analysis confirms an $89 \%$ reduction in prevalent CIN3+; an 88\% reduction in $\mathrm{CIN} 2+$; and a $79 \%$ reduction in CIN1 in vaccinated women born in 1995 and 1996 compared to unvaccinated women born in 1988. Unvaccinated women also showed a lower prevalence of CIN3+ lesions, supporting a herd protection effect. Because of this effect, a reduction in HPV 16/18 infections would not only impact women themselves but also the overall network of sexual relationships between men and women. The fact that the vaccination programme reduced all types of CIN3+ lesions, and not only those related to types 16 and 18 included in the bivalent vaccine, indicates strong cross-protection against other common oncogenic types such as HPV 31/33/45, in accordance with previous clinical trials [102].

Finally, data from registries showing a decrease in cervical cancer are still at a very early stage. Specifically, in Finland, monitoring of cancer registries in vaccinated women in clinical trials and their comparison with unvaccinated cohorts (period 2002/2007-2015) confirms that not a single case was diagnosed in the vaccinated cohort versus 10 cases of HPV-related cancer in the unvaccinated cohort (8 cases of cervical cancer, one vulvar cancer and one oropharyngeal cancer). However, in this analysis the vaccinated and unvaccinated cohorts were not comparable, which limits the interpretation of the data [97].

Another study of the annual incidence of invasive cervical cancer in the United States compares the four years prior to the introduction of the vaccine (2003-2006) with the vaccine era (2011-2014). There was a significant $29 \%$ reduction in average annual incidence rates during the study period (6.0 versus 8.4 per 1,000,000 people, rate ratio $=0.71,95 \% \mathrm{Cl}$ : $0.64-$ 0.80 ) among women aged 15 to 24 years, and $13.0 \%$ lower among women 25 to 34 years. During these years, vaccine coverage increased to $55.3 \%$ in the younger cohorts. Although incidence rates had already declined prior to the introduction of the vaccine, these strongly declining data suggest that it may be partly attributable to the introduction of the HPV vaccine [98]

In relation to the impact on non-genital tumours, in the case of both anal and oropharyngeal cancer, more than 80\% of HPV-associated cases are caused by HPV16, and more than $90 \%$ by at least one of the types 16/18/31/33/45/52/58/6/11. The currently available vaccines would have a very high reduction impact on these two types of cancer. 


\section{Conclusion}

Studies show that with high vaccine coverage (vaccination of more than half of the female population), the burden of HPV infection and related precancerous lesions can be significantly reduced.

The cross-protection against other types not included in the vaccine and the herd effect significantly expand the effect of the vaccines and confer protection to unvaccinated people.

\section{QUESTION: IN AN IDEAL WORLD IN WHICH HEPATITIS C IS ERADICATED, COULD WE ESTIMATE THE DECREASE IN MORTALITY ATTRIBUTABLE TO LIVER TUMOURS? WHAT WOULD BE THE IMPACT ON TUMOUR MORTALITY IN A WORLD WHERE HEPATITIS B VACCINATION WAS UNIVERSAL?}

The question posed is an interesting "epidemiology-fiction" exercise of great future importance and of enormous potential value in terms of public health.

The theoretical substrate of the question is essentially based on the fact that there is no reservoir other than human beings for viruses $B$ and $C$, which encourages the logical hope that their elimination (by the implantation of universal vaccination or by means of antiviral treatment applied to all possible patients) would be capable of clearly attenuating, even until its disappearance, liver diseases associated with chronic viral infection, including primary liver cancer. This attractive concept would be particularly true in an ideal scenario of no new patients with hepatitis $B$ due to vaccination, although the risk of cancer would persist in those patients already infected, in whom screening would still be essential

However, there are several elements that mitigate the undoubted potential impact on the incidence of hepatocellular carcinoma.

i) In patients with advanced hepatitis C, viral suppression does not negate the risk of liver disease progression

Different studies have clearly shown that the sustained viral response in patients treated with direct antivirals has a marked effect on the progression of liver disease in patients in the early stages of infection and that it reduces the risk of complications in patients with more advanced disease. However, in patients with significant portal hypertension (over $10 \mathrm{mmHg}$ ), i.e. those with more advanced disease and at risk of developing complications of cirrhosis, antiviral treatment fails to lower portal pressure below the risk threshold in a significant proportion of patients, the higher it is, the greater the degree of deterioration. Therefore, the risk of developing hepatocellular carcinoma (clearly influenced by the presence of cirrhosis with severe portal hypertension) is not eliminated despite the elimination of the virus in patients with advanced disease.
Therefore, as long as there are patients treated in whom there is basically advanced fibrosis, the risk of developing hepatocellular carcinoma is not zero. There are no data, however, to quantify the safe threshold of fibrosis below which screening would not be necessary

ii) Is antiviral treatment of hepatitis C capable of triggering hepatocellular carcinoma?

This is a very controversial issue arising from the observation in a Spanish multicentre study of an increased frequency of hepatocellular carcinoma recurrence and in its severity in patients with hepatocellular carcinoma treated with radical intent and who immediately afterwards received antiviral treatment for hepatitis $\mathrm{C}$. The researchers speculated about the possible impact of the abrupt suppression of the chronic immune response associated with the cure of the $C$ virus infection with a loss of "anti-tumour surveillance" mediated by immune system cells. Information for and against this hypothesis has emerged since this study. In general, it can be considered that anti-viral treatment does not per se increase the risk of developing hepatocellular carcinoma in patients with cirrhosis with no known tumour. However, delaying the attempt to eradicate the virus in patients recently treated for hepatocellular carcinoma is recommended [103-106].

iii) There are other causes of cirrhosis and hepatocellular carcinoma

As discussed in previous questions, the presence of cirrhosis per se, regardless of its cause, is a pro-oncogenic factor. This is extremely important in patients who are carriers of fatty metabolic liver disease, which is a real epidemic in the Western world. Strikingly, this disease, whose pathogenic complexity and systemic inflammatory substrate are widely known, has its own pro-oncogenic mechanisms. From the epidemiological point of view, it is important to note that patients with hepatocellular carcinoma associated with fatty metabolic liver disease are more frequently observed than in other non-cirrhotic liver aetiologies, are diagnosed in more advanced stages, and are therefore less likely to receive treatment with curative intent. The future impact in terms of increased incidence of hepatocellular carcinoma associated with this disease is not known with certainty, but if the forecasts of increased prevalence worldwide are true, a dramatic increase can be expected in the medium term. In fact, recent studies [107] clearly reinforce this trend.

Ultimately, the impact of a universal elimination of hepatotropic viruses on the development of liver cancer would be of great importance, although it would not completely eliminate this dreaded disease

\section{Conclusion}

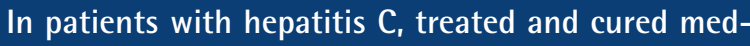
ically, the risk of hepatocellular carcinoma does not disappear and therefore surveillance must be continued.

The hypothetical disappearance of chronic hepatitis B and $C$ virus infections would have an enormous impact on the decrease in liver tumours, which we are unable to put a figure on at present. 


\section{QUESTION: IS THERE A PROSPECT FOR AN EPSTEIN-BARR VIRUS VACCINATION?}

The relationship between viruses and cancer is clearly underestimated and little known, both at the professional level and at the population level, despite such strong data as the fact that the second carcinogen demonstrated worldwide at present is a virus (HPV) [108-115].

Successful and widespread vaccines have been achieved against HBV and HPV, but a widespread vaccine against EBV remains elusive. EBV, as already mentioned, is an oncogenic virus as proven by its association with Burkitt's lymphoma and its ability to transform B cells in vitro [116], through the expression of Epstein-Barr nuclear antigens (EBNA) and latent membrane protein (LMP). EBV-infected cells are also capable of withstanding the cellular lysis of acute infection and this also contributes to neoplastic development.

The lifelong persistence of EBV in humans is a complex multi-step process that begins with infection of the orophar-

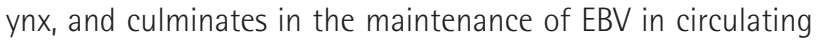
memory B cells. EBV probably uses the normal B-cell differentiation pathway to achieve persistence because it is able to implement various latency and lytic transcription programmes, assuming different antigenic states within infected individuals. However, despite the wide variety of antigens that predominate throughout the EBV life cycle, EBV candidate vaccines have traditionally focused on only a limited number of EBV antigens [117]. plored.

Both therapeutic and prophylactic vaccines have been ex-

Therapeutic vaccines aim to enhance and maintain the immune response in patients with EBV-associated disorders and have been studied mainly in nasopharyngeal carcinoma using dendritic cells with specific CD8 epitopes against LMP2 and using the MVA (Modified Vaccinia Ankara) platform including LMP2 and EBNA 1 antigens [118-120]. The data suggests that tumour growth can be controlled by the immune system $[121,122]$. These studies have led to trials with different therapeutic vaccines that have been well tolerated and the results of phase I and II trials are encouraging but suggest that they are not in themselves the solution for nasopharyngeal carcinoma (the main carcinoma on which these types of vaccines have been tested) as they have an effect on only a low proportion of patients and on a temporary basis [123-126].

The largest number of studies have focused on prophylactic vaccines.

In 1995, a first test was performed with the recombinant attenuated virus itself and did not induce antibodies in seropositive adults. The experts, faced with these results, decided that vaccination was not an appropriate approach to control this virus

Over the past two decades, trials have been based on glycoprotein 350, which led to a phase II trial with a sample size of 181 people. With a three-dose protocol, antibodies re- mained for 18 months and the incidence of infectious mononucleosis was reduced by $78 \%$ but the vaccine did not reduce the risk of acquiring EBV infection [117].

Work has also been done with a vaccine based on glycoprotein 350 for its pre-kidney transplant application in children that was not very immunogenic $[127,128]$.

Similar data were obtained to the Phase II trial with a vaccine using the toxoid conjugated EBNA3 nuclear antigen designed to elicit specific T-cell responses to EBV, but it also failed to prevent EBV infection. It should be noted that this vaccine is very simple to perform due to the simplicity of the antigen [129].

Antigen-antibody conjugates, or antigen-armed antibodies (AgAbs), which specifically deliver antigenic peptides to antigenic cells [130], have also been used as vaccine candidates without conclusive results.

EBV antigens have also been introduced in virus-like particles $[107,108]$ and in self-assembling nanoparticles. These platforms allow monomeric antigens to be similar to EBV, but as they lack DNA they are not infectious. Chimeric viruses are also achieved by the fusion of EBV antigens with the structural proteins of Newcastle disease virus. In these structures, for example, gp350 induces a greater response to vaccination [116, 131-137].

All these studies leave us a long way from achieving an effective vaccine against EBV and its primary diseases and, more importantly, against its ability to induce tumour processes.

\section{Conclusion}

Despite promising results, neither therapeutically oriented vaccines for nasopharyngeal carcinoma nor preventive vaccines to avoid primary infection by EBV have yet demonstrated sufficient levels of protection to be considered close to market entry.

\section{QUESTION: WHAT ARE ONCOLYTIC VIRUSES? WHAT ARE THE PROSPECTS FOR TREATMENT WITH THEM?}

An oncolytic virus is a virus that preferentially infects and kills cancer cells. As the infected cancer cells are destroyed, the oncolysis releases new viral particles that help destroy the remaining tumour.

The potential of viruses as anti-cancer agents was first discovered in the early 20th century, although coordinated research efforts did not begin until the 1960s. Several viruses, including adenovirus, reovirus, measles virus, HVS, Newcastle disease virus, and others, have been clinically tested as oncolytic agents.

Most current oncolytic viruses are designed to be selective against tumour cells, although there are naturally occurring examples, such as Reovirus and Senecavirus, that have been used in clinical trials. 
The acquisition of virus selectivity by the tumour cell can be obtained by modifying the proteins of the viral capsid, giving it a high selectivity by the tumour cells. It can also be achieved by modifying the virus genome so that replication only takes place inside the tumour cell. This is achieved either by modifying the transcription in the target cell, or by attenuation, which involves introducing deletions in the viral genome to favour its entry into the tumour cells and eliminate its ability to penetrate healthy cells. It is also possible to introduce genes into oncolytic viruses that encode the synthesis of endostatin and angiostatin, natural proteins that inhibit angiogenesis, with the consequent necrosis of the tumour.

Oncolytic viruses not only cause direct destruction of tumour cells, but also stimulate the host's anti-tumour immune system responses. Most are genetically modified to increase tumour tropism and reduce virulence for non-neoplastic host cells [138]. Thus, they can stimulate a pro-inflammatory environment by improving antigen release/recognition and subsequent immune activation to counteract immune evasion by malignant cells. In fact, oncological tic viruses also aim to take advantage of the tumour's tolerance mechanisms, which can facilitate viral infection and the death of cells that are not protected by the immune system. This allows for a theoretical domino effect involving chained viral transfer between the neoplastic cells and increased immune activation.

There are currently numerous viral species in different stages of research for immuno-oncological use. Possibly the best studied so far are herpes viruses, of which some strains have been found to have a tropism for natural tumour cells while others have been designed to improve selectivity [139143]. Initial scans using herpes have shown promising results in murine glioblastoma. Additional efficacy has been seen in prostate cancer, using a recombinant smallpox-vaccine virus capable of regulating prostate-specific antigen and the expression of three co-stimulating factors involved in the presence of the antigen and activation of T cells $[144,145]$. In addition, several strains of recombinant vaccine virus have shown promise as antineoplastic agents. One strain has anti-tumour angiogenesis, another has shown efficacy against hepatocellular carcinoma in animal models and the third improves the recognition of tumour cells [146-149]. Other viruses have been or are being explored as possible vehicles of immunomodulation in cancer, such as Newcastle disease virus, coxsackievirus, reovirus, and even the measles virus [150-153].

Among those approved for treatment by the FDA is Talimogene laherparepvec (OncoVEX GM-CSF), also known as T-vec, from Amgen which successfully completed phase III trials for advanced melanoma in March 2013. In October 2015, the U.S. Food and Drug Administration approved T-vec, under the brand name Imlygic ${ }^{\circledR}$, for the treatment of melanoma in patients with inoperable tumours, becoming the first approved oncolytic agent in the Western world. It is based on the Herpes simplex virus (HSV-1). It has also been tested in a Phase I trial for pancreatic cancer and in a Phase III trial in head and neck cancer along with chemotherapy and radiotherapy with cisplatin.
Oncolytic viruses are generally associated therapeutically with other therapeutic strategies such as association with checkpoint inhibitors, Ipilimumab, Pembrolizumab, Atezolizumab, anti-tumour lymphocytes (CAR-T) or associations of oncolytic viruses with tumour epitopes: vaccines.

Clinical trials with oncolytic viruses in entities as different as colorectal cancer, glioblastoma, tumours with widespread metastases, pancreatic cancer, bladder cancer, ovarian cancer or primary tumours of the peritoneum are underway and represent a hope for the therapeutic future of these malignancies.

\section{Conclusion}

Oncolytic viruses are natural viruses, or artificially engineered in the laboratory, with selective tropism for tumour cells. They belong to different viral groups, acting selectively with different action mechanisms. Some have been approved for clinical use in humans and are already being used in some tumours, usually in association with chemotherapy or monoclonal antibodies.

\section{QUESTION: WHAT IS THE COST TO HEALTH CARE SYSTEMS OF TUMOURS DUE TO VIRUSES THAT COULD HAVE BEEN AVOIDED? WHAT ROLE SHOULD HEALTH AUTHORITIES PLAY IN APPROACHING THIS ISSUE?}

In addition to the human cost of cancer, the financial cost is considerable. Direct costs include treatment expenses as well as the cost of care and rehabilitation. Indirect costs include the loss of economic output due to work lost and premature death. There are also costs that are difficult to quantify such as non-medical costs. The exact global cost of cancer is unknown but is expected to increase due to the increase in the number of new cancer cases, as well as the rising cost of cancer therapies $[17,154,155]$

The health authorities must act on this issue, fundamentally modifying the prevention of risk factors and implementing preventive strategies.

The risk factors for the most immediate intervention are the decrease in genital HPV infections where, among other means, it is possible to intervene with vaccines and vaccination and the treatment of hepatitis virus infections $[156,157]$.

\section{Conclusion}

The expenditure associated with cancers caused by infectious agents and particularly by viruses is difficult to quantify, but is high and clearly increasing.

The health authorities can intervene by means of prevention and vaccination campaigns, preferably with vaccination against HPV and Hepatitis B and through the treatment of Hepatitis C. 


\section{QUESTION: IS THE PRESS AWARE OF THIS ISSUE? WHAT ROLE SHOULD IT PLAY?}

Over the last ten years, the press and media have reduced the resources, spaces and personnel dedicated to generating, producing and writing health and medical content as a result of the economic crisis that affected them both through the closure of companies and newspaper titles, as well as through financial adjustments and staff cuts.

Training and specialisation levels have also been reduced in the health, sanitation and science sections for the same reasons.

Despite the variability of the economic crisis, the media have not recovered lost ground and continue to be immersed in situations of weakness and economic-financial fragility.

The impact of new technologies -no longer so new- and the possibilities they have offered for opening up the publication of content to society, as well as the appearance of new communication channels, have posed a risk for the media and threat of loss or dissolution of their preponderant role as the central and principal reference of information for society, having to compete with platforms such as the internet -in its broadest facet of distribution of all kinds of products-, social networks and so-called citizen journalism.

Despite these circumstances, the press and media have placed cancer and everything related to this disease at the forefront of relevance and interest with respect to health and healthcare issues and content, giving it a media prominence above other diseases, with a broad and compact informative approach that considers angles and approaches ranging from health policy, the variety of tumours, the role of patients, research and scientific advances, the work of medical-scientific societies and the oncology sector, the activity of health or pharmaceutical centres and companies, the commemoration of World Days, etc.

"Journalism loves cancer" would be the quick and easy headline.

Having thus explained and exposed the prominence of cancer in the press and media with a broad, diversified and comprehensive scope, it must also be said that viruses, infections, their prognosis, their effects and their medical and social impact as a public health issue are also a subject of strong media coverage, such as flu, AIDS and hepatitis.

However - and here we have the paradox of two related worlds that are disconnected both in the media and in society -, despite the many studies and evidence that link and concatenate the viruses with cancer, the information, dissemination, knowledge and content provided by the media in their health and cancer information to society hardly connect these two aspects, unlike others such as cancer-smoking, or cancer-ageing.

The role of vaccines, at a time when the anti-vaccine movements are rearming and advancing, first on social networks and then in society, is also decisive in this issue, and while the big question in the popular imagination continues to be whether a cancer vaccine will ever be discovered, medicine has some that serve to curb certain tumours.

Thus, the press and the media neither transmit nor have great knowledge about the binomial subject of study of this Symposium; they do not dedicate special time, space, resources or contents (informative or educational) to this specific angle of the many news stories they publish about cancer.

We suggest, therefore, some measures from the media to report on cancer and viruses

- Include in the news coverage on cancer - which is widespread and frequent - information related to its relationship with viruses, either as emergent or underlying information. It is an aspect that matters to society and so the media should not ignore it.

- Investigate and activate content on the virus / cancer binomial from the editorial planning boards, with reliable and specialised sources.

- To broaden the sense of disclosure on medicine, diseases, prevention and research, beyond the information resulting from announcements, reports or campaigns; and to emphasise this treatment of the contents.

- Combat health and cancer myths and 'fake news' with rigorous, clear and accurate verification practices to stop confusion, poor news and information gaps.

- The press and media are undoubtedly committed to the fight against cancer and include news coverage in their agendas and work strategies, but the relationship between oncological diseases and viruses must have greater incidence, reach, development and presence.

\section{Conclusion}

Despite frequent and relevant information in the media about cancer on the one hand and viral infections on the other, information about the association between viruses and cancer in the media rarely connects these two aspects, unlike others such as cancer-smoking or cancer-ageing.

\section{QUESTION: HOW IS THE VIRUS CANCER RELATIONSHIP EXPERIENCED, FROM THE PERSPECTIVE OF THE SPANISH PATIENTS WITH CANCER GROUP, GEPAC?}

The Virus and Cancer association is little known by the population and information from cancer patient associations is also partial and deficient in this respect. Therefore, a great deal of educational and informative work remains to be done in this area. This absence often forces one to turn to "Doctor Google" for information, which can lead to misinformation, since one does not know which sites are reliable, or does not have sufficient knowledge to fully understand and interpret the data that appear. 
Probably what resonates most with patients, families and society at large are associations such as HPV, HBV or HIV and cancer. According to the U.S. National Cancer Institute, "Certain infectious germs, including viruses, bacteria and parasites, can cause cancer or increase the risk of tumour formation. Also, some infections weaken the immune system, making the body less able to fight other infections that cause cancer. Some viruses, bacteria and parasites also cause chronic inflammation that can lead to cancer [158-160].

With no knowledge of these basic facts, it should not be surprising that the social demand and requirement by patients and associations for adequate vaccines, when they exist, is also not of an appropriate intensity. It is often ignored that protection with a condom is not always sufficient for the prevention of all types of sexually transmitted viruses, in addition to limiting sexual partners.

GEPAC wants to highlight the need for sex education for the prevention of STDs, to teach safe sexual practices, care for personal health and our sexual partners. If we are informed, we know all the ways of contagion and we are aware of the importance of medical check-ups if we live in dangerous situations; we can reduce the number of people affected by this type of illness.

It should be noted that most of the viruses that can pose a cancer risk can be transmitted through certain body fluids or blood. And not only that, this type of virus and thus disease, in addition to the health problems they entail, are linked to psychological repercussions that will depend on the severity of your situation, symptoms and treatment received.

In addition, it can lead to anxiety, depression, or feelings of guilt or fear of criticism due to the social stigma. Perhaps guilt is the most difficult emotion to handle in a situation where the contraction of a virus seems to be linked to risky sexual practices.

For all these reasons, we can conclude that only by educating young people and working with the groups most at risk will we be able to have informed adults in the future and thus reduce cases of infection.

\section{Conclusion}

Patient associations should contribute to the dissemination of the relationship between viruses and cancer and of existing preventive measures, including vaccines, which have been shown to be effective in preventing avoidable cancers.

\section{QUESTION: WHAT ARE THE REFLECTIONS ON THE VIRUS CANCER RELATIONSHIP FROM AN ETHICAL PERSPECTIVE?}

Classical medical training, the one we received in medical schools, has been and is the victim of a bias that vitiates many of our approaches to issues such as the one raised here, that of the relationship between viruses and cancer. It is a bias that did not exist in classical medicine but has become invasive since the early 19th century. The advances in experimental research made it possible from that moment on to describe with great precision the pathognomonic symptoms of some diseases, almost at the same time as their causal agents were found. Think, for example, of the microorganisms that were identified by the dozens in the late 19th century, and which led to the utopia of thinking that each morbid species would be produced by a specific agent: meningitis by meningococcus, pneumonia by pneumococcus, etc. On the other hand, the advances in experimental pharmacology allowed the identification of the first "specific" drugs that acted against the aetiological agents that produced diseases, leaving all other organic structures unharmed. It was the dream of Béchamp's "atoxyl" and Ehrlich's "magic bullets".

At the heart of all this was an unconscious presupposition, that of "specificity". Diseases were species like those in botany and zoology. A catalogue of diseases similar to Linnaeus's Systema Naturæ, the catalogue of "morbid species", could therefore be drawn up. Each of them would have a "specific aetiology", which, for example, microbiology would discover, and "specific therapeutics" would also begin to be found, which by attacking the cause of the disease, would restore the state of health. It was therefore a linear process, starting with a specific cause, continuing with the clinical picture of a morbid species and ending with the application of a specific treatment. It was the chain of specificity. The role of medicine was to find the remedies, usually pharmacological, that would act on the specific agent and allow "restitutio ad integrum". A paradigmatic example of this is pulmonary tuberculosis. The clinical picture of this disease, which was very common at the time of the industrial revolution, was described with great precision by the great masters of the anatomical clinical method, including Laënnec. Koch identified the bacillus that caused it, and later, in the mid-20th century, the first specific treatment, streptomycin, was developed. From that moment on, every doctor knew what he had to do: use that antibiotic, and the tuberculosis and TB drugs that came soon after, to kill the Koch bacillus and thus cure the disease.

But the example of tuberculosis is very illustrative of the limitations of this way of understanding the disease. I still remember the debates about tuberculosis from my time as a medical student in the 1960s. Could it be said that TB was caused by Koch's bacillus? Wasn't it also true that pauperism, malnutrition, poor hygiene, etc., played a role? What was the cause of the tuberculosis? Was it just one or was it many? And how to articulate them?

I have brought this example to mind because it is very illustrative of the way in which school medicine has understood illness, and because it expresses very well the so-called "chain of specificity". TB is caused by Koch's bacillus. If we eradicated it, there would be no pulmonary tuberculosis, even with pauperism, malnutrition, etc. These, on the other hand, are not strictly medical issues, but social ones.

Let us now turn to our problem, that of viruses and can- 
cer. It is clear that cancer is the result of genetic dysregulation. This alteration is produced by various agents, including viruses. If we were able to eliminate these or correct the alterations, they produce in the genome by means of gene editing techniques, some, if not all, of the important types of cancer would disappear. That is the goal of medicine, and that is the aim of the research being done today. It is, again, the linear scheme, the chain of specificity.

Things are, however, more complex. There is no single causal factor. In fact, this term should disappear from our vocabulary, or at least become a discreet second term. Cause is what necessarily produces an effect, so that even if all the concomitant factors were to disappear, the effect would be produced by it alone. Something impossible to affirm in the empirical world. What we know are not causes, even if they seem to be, but functional correlations. In fact, all experimental research aims to identify them as precisely as possible. They are correlations, not causes. And among these correlations, there is no doubt that the Koch bacillus plays an important role, but so do immunity and environmental conditions, etc. In fact, not every person infected with Koch's bacillus develops tuberculosis.

Rather than establishing a linear relationship between cause, clinical picture and therapy, it is necessary to make use of more complex schemes, of a circular or at least spiral nature. In the genesis of cancer, endogenous factors intervene, such as the genome we have, but also exogenous factors. The fact is that viruses are some of those exogenous factors that infect cells and alter their genetic information. There are many other exogenous factors that produce similar results. Think of radiation, for example, or tobacco. These are the factors that can be called direct. But there are many other indirect factors. Thus, tobacco is a direct agent in the case of certain lung cancers but acts as an indirect agent in hepatocellular carcinoma. And along with tobacco and alcohol, place sexual habits in the case of infection by the human papillomavirus, food habits in fatty liver and the increased likelihood of liver cancer, etc.

The conclusion of all this already long journey is that life habits are important factors in the genesis of cancer, in some cases indirectly, through viruses, and in others directly. This seems elementary, but it is far from clear, not only in the population, but even among doctors. We believe that what is important is the control of the gene alterations that trigger uncontrolled cell reproduction, and that the other is not a question of medicine. And we lose sight of the fact that rather than being curative, medicine should be preventative. The dizzying increase in its therapeutic capacity is making us forget this primary truth. The primary role of the physician is not cure but prevention; health education is preferable. Otherwise, we arrive at the absurdity that we live and suffer every day. This is the case of the diabetic who eats cakes because this can be fixed by increasing the dose of insulin, or the loss of respect for HIV because we already have effective therapies.

Prevention, or rather, health education, is not just about information. That is one of the great mistakes that have be- come almost universal. Educating is far more difficult and complicated than informing. Education is always about knowing how to manage one's own life autonomously and prudently. It's knowing how to make the right decisions. Or to put it another way, it's making the choices we have to make. And here's the ethics. The aim of this discipline is none other than to teach us how to make decisions, the right decisions, so that we do what we have to do. The big question of ethics is always the same: what should I do? And there can only be one answer: among all the possible courses of action in a given situation, only the decision that leads to the optimal course is good or correct, that is, the one which adheres to the values at stake most and injures them least. Only the optimum course is good. Everything else is bad. A good surgeon is the one who performs the best possible operation, and a good judge is the one who passes the best possible sentence, etc. To know how to do this, and do it well, is to be educated. This is not easy, because the human mind is full of dark areas, those that Freud called unconscious, that skew our decisions without us noticing. Good education is the art of managing all these factors properly so that our decisions are the best they can possibly be. This, and no other, is the goal of ethics.

\section{Conclusion}

Even though cancer does have a genetic basis, the triggers, including viruses, are always external to the genome itself. A very common mentality in medicine leads to linear thinking, reducing the aetiology to the genetic disorder and the therapy to the correction of that disorder. However, things are more complicated. The genome itself is the result of interactions with the environment, meaning that health depends not only on the genome but also on our lifestyle. And that is precisely the objective of ethics: to educate in the prudent and responsible management of the body, health, life and death.

\section{REFERENCES}

1. Hill AB. The Environment and Disease: Association or causation? Proc R Soc Med. 1965;58:295-300. PMID: 14283879

2. Martin D, Gutkind JS. Human tumor-associated viruses and new insights into the molecular mechanisms of cancer. Oncogene. 2008;27 Suppl 2:S31-42. DOI: 10.1038/onc.2009.351

3. Mukherjee S. Cancer, Our Genes, And The Anxiety Of Risk-Based Medicine. Health affairs (Project Hope). 2018;37(5):817-20. DOI: 10.1377/hlthaff.2018.0344

4. Weinberg RA. The Biology of Cancer. The Biology of Cancer, second edition. 2013. :

5. Rubin $H_{1}$ Temin HM, Rubin $H_{1}$ Temin HM, Temin HM, Rubin $H_{\text {, et }}$ al. Infection with the Rous sarcoma virus in vitro. A radiological study of cell-virus interaction in the Rous sarcoma. Characteristics of an assay for Rous sarcoma virus and Rous sarcoma cells in tissue culture. A kinetic study of infection of chick embryo cells in vitro by Rous sarcoma virus. Fed Proc. 1958;17(4):994-1003. D0I: 10.1016/0042-6822(59)90178-3. 
6. Rubin $\mathrm{H}_{1}$ Temin HM. A radiological study of cell-virus interaction in the Rous sarcoma. Virology. 1959;7(1):75-91. DOI: 10.1016/00426822(59)90178-3

7. DiMaio D, Liao JB. Human papillomaviruses and cervical cancer. Adv Virus Res. 2006;66:125-59. DOI: 10.1016/s0065-3527(06)66003-X

8. Stone RS, Shope RE, Moore DH. Electron microscope study of the development of the papilloma virus in the skin of the rabbit. J Exp Med. 1959;110(4):543-6. DOI: 10.1084/jem.110.4.543

9. Moore DH, Stone RS, Shope RE, Gelber D. Ultrastructure and site of formation of rabbit papilloma virus. Proc Soc Exp Biol Med. 1959;101(3):575-8. D0I: 10.3181/00379727-101-25022

10. Raj AT, Patil S, Gupta AA, Rajkumar C, Awan KH. Reviewing the role of human papillomavirus in oral cancer using the Bradford Hill criteria of causation. Disease-a-month : DM. 2019;65(6):155-63. DOI: 10.1016/j.disamonth.2018.09.007

11. Varmus HE, Guntaka RV, Fan WJ, Heasley S, Bishop JM. Synthesis of viral DNA in the cytoplasm of duck embryo fibroblasts and in enucleated cells after infection by avian sarcoma virus. Proc Natl Acad Sci U S A. 1974;71(10):3874-8. DOI: 10.1073/pnas.71.10.3874

12. Bishop JM, Quintrell $N$, Medeiros E, Varmus HE. Of birds and mice and men: comments on the use of animal models and molecular hybridization in the search for human tumor viruses. Cancer. 1974;34(4 Suppl):suppl:1421-6. DOI: $\quad$ 10.1002/1097-0142(197410)34:8+<1421::aid-cncr2820340813>3.0.co;2-0

13. Varmus HE, Heasley $\mathrm{S}$, Bishop JM. Use of DNA-DNA annealing to detect new virus-specific DNA sequences in chicken embryo fibroblasts after infection by avian sarcoma virus. J Virol. 1974;14(4):895-903. DOI:

14. Brower V. Connecting viruses to cancer: how research moves from association to causation. J Natl Cancer Inst. 2004;96(4):256-7. DOI: 10.1093/jnci/96.4.256

15. Organization. IAfRoCWH. Section of Infections Infections and Cancer Epidemiology Group Rationale. [cited 10 April 2021] https:// wwwiarcfr/research-groups-inf-ice-rationale/. 2019.

16. Plummer $M$, de Martel $C$, Vignat J, Ferlay J, Bray F, Franceschi S. Global burden of cancers attributable to infections in 2012: a synthetic analysis. Lancet Glob Health. 2016;4(9):e609-16. DOI: 10.1016/s2214-109x(16)30143-7

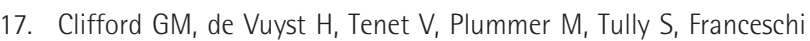
S. Effect of HIV Infection on Human Papillomavirus Types Causing Invasive Cervical Cancer in Africa. J Acquir Immune Defic Syndr. 2016;73(3):332-9. DOI: 10.1097/qai.0000000000001113

18. Qian MB, Zhou XN. Global burden of cancers attributable to liver flukes. Lancet Glob Health. 2017;5(2):e139. DOI: 10.1016/s2214109x(16)30301-1

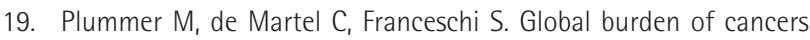
attributable to liver flukes - Authors' reply. Lancet Glob Health. 2017;5(2):e140. DOI: 10.1016/s2214-109x(16)30293-5

20. Shield KD, Marant Micallef $C$, de Martel $C$, Heard I, Megraud F, Plummer $M_{1}$ et al. New cancer cases in France in 2015 attributable to infectious agents: a systematic review and meta-analysis. Eur J Epidemiol. 2018;33(3):263-74. DOI: 10.1007/s10654-017-0334-Z
21. Parkin DM. 11. Cancers attributable to infection in the UK in 2010. Brit J Cancer. 2011;105 Suppl 2:S49-56. DOI: 10.1038/bjc.2011.484

22. Antonsson A, Wilson LF, Kendall BJ, Bain CJ, Whiteman DC, Neale RE. Cancers in Australia in 2010 attributable to infectious agents. Aust N Z J Public Health. 2015;39(5):446-51. DOI: 10.1111/17536405.12445

23. Ndiaye $\mathrm{C}$, Mena $\mathrm{M}$, Alemany $\mathrm{L}$, Arbyn $\mathrm{M}$, Castellsague $\mathrm{X}$, Laporte $\mathrm{L}$, et al. HPV DNA, E6/E7 mRNA, and p16INK4a detection in head and neck cancers: a systematic review and meta-analysis. Lancet Oncol. 2014;15(12):1319-31. DOI: 10.1016/s1470-2045(14)70471-1

24. Parkin DM, Hammerl L, Ferlay J, Kantelhardt EJ. Cancer in Africa 2018: The role of infections. Int J Cancer. 2020;146(8):2089-103. DOI: $10.1002 /$ ijc.32538

25. Kim SM. Human papilloma virus in oral cancer. J Korean Assoc Oral Maxillofac Surg. 2016;42(6):327-36. DOI: 10.5125/jkaoms.2016.42.6.327

26. Morales-Sanchez A, Fuentes-Panana EM. Epstein-Barr Virus-associated Gastric Cancer and Potential Mechanisms of Oncogenesis. Curr Cancer Drug Targets. 2017;17(6):534-54. DOI: 10.2174/15680 09616666160926124923

27. Saeed M, Alshammari FD, Alam MJ, Sarim KM, Ahmad K, Hussain T, et al. A Synopsis on the Role of Human Papilloma Virus Infection in Cervical Cancer. Curr Drug Metab. 2018;19(9):798-805. D0I: 10.21 74/1389200219666180302160317

28. Cobbs C. Cytomegalovirus is a tumor-associated virus: armed and dangerous. Curr Op Virol. 2019;39:49-59. DOI: 10.1016/j.coviro.2019.08.003

29. Yang Z, Wang J, Zhang Z, Tang F. Epstein-Barr Virus-Encoded Products Promote Circulating Tumor Cell Generation: A Novel Mechanism of Nasopharyngeal Carcinoma Metastasis. Onco Targets Ther. 2019;12:11793-804. DOI: 10.2147/ott.S235948

30. Fernandes Q, Gupta I, Vranic S, Al Moustafa AE. Human Papillomaviruses and Epstein-Barr Virus Interactions in Colorectal Cancer: A Brief Review. Pathogens. 2020;9(4). DOI: 10.3390/pathogens9040300

31. Islam MS, Chakraborty B, Panda CK. Human papilloma virus (HPV) profiles in breast cancer: future management. Ann Transl Med. 2020;8(10):650. DOI: 10.21037/atm-19-2756

32. de Martel C, Plummer M, Vignat J, Franceschi S. Worldwide burden of cancer attributable to HPV by site, country and HPV type. Int J Cancer. 2017;141(4):664-70. DOI: 10.1002/ijc.30716

33. Ervik M ea. Cancer Today. Lyon, France: International Agency for Research on Cancer.. Cancer Today. 2016; [cited 10 April 2021] ->http://go.iarc.fr/today.

34. Hartwig S, St Guily JL, Dominiak-Felden G, Alemany L, de Sanjose S. Estimation of the overall burden of cancers, precancerous lesions, and genital warts attributable to 9-valent HPV vaccine types in women and men in Europe. Infect Agents Cancer. 2017;12:19. DOI: 10.1186/s13027-017-0129-6

35. Syrjänen S. Human papillomavirus (HPV) in head and neck cancer. J Clin Virol. 2005;32 Suppl 1:S59-66. DOI: 10.1016/j.jcv.2004.11.017

36. Virzi A, Roca Suarez AA, Baumert TF, Lupberger J. Oncogenic Signa- 
ling Induced by HCV Infection. Viruses. 2018;10(10). DOI: 10.3390/ v10100538

37. Kanwal $F$, Singal AG. Surveillance for Hepatocellular Carcinoma: Current Best Practice and Future Direction. Gastroenterology. 2019;157(1):54-64. D0I: 10.1053/j.gastro.2019.02.049

38. Kanda $T$, Goto $T$, Hirotsu $Y$, Moriyama M, Omata M. Molecular Mechanisms Driving Progression of Liver Cirrhosis towards Hepatocellular Carcinoma in Chronic Hepatitis B and C Infections: A Review. Int J Mol Sci. 2019;20(6). DOI: 10.3390/ijms20061358

39. Zhang LL, Wei JY, Wang L, Huang SL, Chen JL. Human T-cell lymphotropic virus type 1 and its oncogenesis. Acta Pharmacol Sin. 2017;38(8):1093-103. DOI: 10.1038/aps.2017.17

40. Phillips AA, Harewood JCK. Adult T Cell Leukemia-Lymphoma (ATL): State of the Art. Curr Hematol Malig Rep. 2018;13(4):300-7. DOI: 10.1007/s11899-018-0458-6

41. Shimoyama M, Kagami $Y$, Shimotohno $K_{1}$ Miwa M, Minato $K_{1}$ Tobinai $K_{1}$ et al. Adult T-cell leukemia/lymphoma not associated with human T-cell leukemia virus type I. Proc Natl Acad Sci U S A. 1986;83(12):4524-8. D0I: 10.1073/pnas.83.12.4524

42. Shimoyama M, Minato K, Tobinai $K$, Nagai M, Setoya T, Takenaka $T$, et al. Atypical adult T-cell leukemia-lymphoma: diverse clinical manifestations of adult T-cell leukemia-lymphoma. Jpn J Clin Oncol. 1983;13 Suppl 2:165-87. DOI:

43. Brickman C, Palefsky JM. Cancer in the HIV-Infected Host: Epidemiology and Pathogenesis in the Antiretroviral Era. Curr HIV/AIDS Rep. 2015;12(4):388-96. DOI: 10.1007/s11904-015-0283-7

44. Shepherd L, Borges Á, Ledergerber B, Domingo P, Castagna A, Rockstroh J, et al. Infection-related and -unrelated malignancies, HIV and the aging population. HIV Med. 2016;17(8):590-600. DOI: 10.1111/hiv. 12359

45. Garcia-Abellan J, Del Rio L, Garcia JA, Padilla S, Vivancos MJ, Del Romero J, et al. Risk of cancer in HIV-infected patients in Spain, 2004-2015. The CoRIS cohort study. Enferm Infecc Microbiol Clin. 2019;37(8):502-8. DOI: 10.1016/j.eimc.2018.11.011

46. Montejano R, Alejos B , Bernardino JI , De Miguel Buckley R, Martin-Carbonero $L$, Busca $C$, et al., editors. Aids defining and non-defining cancers in persons living with HIV in a single centre cohort followed since 1986. 17th European AIDS Conference; 2019; Basel.

47. Lopez C, Masia M, Padilla S, Aquilino A, Bas C, Gutierrez F. [Deaths due to non-AIDS diseases among HIV infected patients: A 14-year study (1998-2011)]. Enferm Infecc Microbiol Clin. 2016;34(4):2227. DOI: 10.1016/j.eimc.2015.04.010

48. Engels EA, Yanik EL, Wheeler W, Gill MJ, Shiels MS, Dubrow R, et al. Cancer-Attributable Mortality Among People With Treated Human Immunodeficiency Virus Infection in North America. Clin Infect Dis. 2017;65(4):636-43. DOI: 10.1093/cid/cix392

49. Gotti D, Raffetti E, Albini L, Sighinolfi L, Maggiolo F, Di Filippo E, et al. Survival in HIV-infected patients after a cancer diagnosis in the cART Era: results of an italian multicenter study. PloS one. 2014;9(4):e94768. DOI: 10.1371/journal.pone.0094768

50. Trepka MJ, Auf R, Fennie KP, Sheehan DM, Maddox LM, Niyonsenga T. Deaths Due to Screenable Cancers Among People Living With HIV Infection, Florida, 2000-2014. Am J Prev Med. 2017;53(5):705-9.

\section{DOI: 10.1016/j.amepre.2017.05.018}

51. Cevallos ea. Causas de mortalidad en la población infectada por el Virus de la Inmunodeficiencia Humana en la Comunidad de Madrid (2007-2014). Lin at https://wwwrevistamultidisciplinardelsidacom/causas-de-mortalidad-en-la-poblacion-infectada-por-el-virus-de-la-inmunodeficiencia-humana-en-la-comunidad-de-madrid-2007-2014/.

52. Croxford S, Miller RF, Post FA, Harding R, Lucas SB, Figueroa J, et al. Cause of death among HIV patients in London in 2016. HIV Med. 2019;20(9):628-33. DOI: 10.1111/hiv.12761

53. Ozoya 00, Sokol L, Dalia S. EBV-Related Malignancies, Outcomes and Novel Prevention Strategies. Infect Disord Drug Targets. 2016;16(1):4-21. DOI: 10.2174/1871526516666160407113536

54. Manners O, Murphy JC, Coleman A, Hughes DJ, Whitehouse A. Contribution of the KSHV and EBV lytic cycles to tumourigenesis. Curr Op Virol. 2018;32:60-70. DOI: 10.1016/j.coviro.2018.08.014

55. Kanda T, Yajima M, Ikuta K. Epstein-Barr virus strain variation and cancer. Cancer Sci. 2019;110(4):1132-9. DOI: 10.1111/cas.13954

56. Smith JS, Herrero R, Bosetti C, Munoz N, Bosch FX, Eluf-Neto J, et al. Herpes simplex virus-2 as a human papillomavirus cofactor in the etiology of invasive cervical cancer. J Natl Cancer Inst. 2002;94(21):1604-13. DOI: 10.1093/jnci/94.21.1604

57. Thorley-Lawson DA, Gross A. Persistence of the Epstein-Barr virus and the origins of associated lymphomas. New Eng J Med. 2004;350(13):1328-37. DOI: 10.1056/NEJMra032015

58. Dierickx D, Habermann TM. Post-Transplantation Lymphoproliferative Disorders in Adults. New Eng J Med. 2018;378(6):549-62. DOI: 10.1056/NEJMra1702693

59. Chua MLK, Wee JTS, Hui EP, Chan ATC. Nasopharyngeal carcinoma. Lancet (London, England). 2016;387(10022):1012-24. DOI: 10.1016/s0140-6736(15)00055-0

60. Andersson-Anvret M, Forsby N, Klein G, Henle W, Biorklund A. Relationship between the Epstein-Barr virus genome and nasopharyngeal carcinoma in Caucasian patients. Int J Cancer. 1979;23(6):7627. DOI: 10.1002/ijc.2910230605

61. Pallesen G, Hamilton-Dutoit SJ, Rowe M, Young LS. Expression of Epstein-Barr virus latent gene products in tumour cells of Hodgkin's disease. Lancet (London, England). 1991;337(8737):320-2. DOI: 10.1016/0140-6736(91)90943-j

62. Cheung MM, Chan JK, Lau WH, Foo W, Chan PT, Ng CS, et al. Primary non-Hodgkin's lymphoma of the nose and nasopharynx: clinical features, tumor immunophenotype, and treatment outcome in 113 patients. J Clin Oncol. 1998;16(1):70-7. DOI: 10.1200/ jco.1998.16.1.70

63. Purushothaman P, Uppal T, Sarkar R, Verma SC. KSHV-Mediated Angiogenesis in Tumor Progression. Viruses. 2016;8(7). DOI: 10.3390/v8070198

64. Martin JN, Ganem DE, Osmond DH, Page-Shafer KA, Macrae D, Kedes DH. Sexual transmission and the natural history of human herpesvirus 8 infection. New Eng J Med. 1998;338(14):948-54. DOI: 10.1056/nejm 199804023381403

65. Munoz P, Alvarez P, de Ory F, Pozo F, Rivera M, Bouza E. Incidence 
and clinical characteristics of Kaposi sarcoma after solid organ transplantation in Spain: importance of seroconversion against HHV-8. Medicine. 2002;81(4):293-304. DOI: 10.1097/00005792200207000-00005

66. Stallone G, Schena A, Infante B, Di Paolo S, Loverre A, Maggio G, et al. Sirolimus for Kaposi's sarcoma in renal-transplant recipients. New Eng J Med. 2005;352(13):1317-23. DOI: 10.1056/NEJMoa042831

67. Dittmer DP, Damania B. Kaposi's Sarcoma-Associated Herpesvirus (KSHV)-Associated Disease in the AIDS Patient: An Update. Cancer Treat Res. 2019;177:63-80. DOI: 10.1007/978-3-030-03502-0_3

68. Lodi S, Guiguet M, Costagliola D, Fisher M, de Luca A, Porter K. Kaposi sarcoma incidence and survival among HIV-infected homosexual men after HIV seroconversion. J Natl Cancer Inst. 2010;102(11):784-92. DOI: 10.1093/jnci/djq134

69. Engels EA, Pfeiffer RM, Goedert JJ, Virgo P, McNeel TS, Scoppa SM, et al. Trends in cancer risk among people with AIDS in the United States 1980-2002. AIDS (London, England). 2006;20(12):1645-54. DOI: 10.1097/01.aids.0000238411.75324.59

70. Jung JM, Lee KH, Kim YJ, Chang SE, Lee MW, Choi JH, et al. Assessment of Overall and Specific Cancer Risks in Patients With Hidradenitis Suppurativa. JAMA Dermatol. 2020. DOI: 10.1001/jamadermatol.2020.1422

71. Lapins J, Ye W, Nyrén O, Emtestam L. Incidence of cancer among patients with hidradenitis suppurativa. Arch Dermatol. 2001;137(6):730-4. DOI:

72. Zhan P, Suo L, Qian $Q_{\text {, Shen } X K}$, Qiu LX, Yu LK, et al. Chlamydia pneumoniae infection and lung cancer risk: a meta-analysis. Eur J Cancer. 2011;47(5):742-7. DOI: 10.1016/j.ejca.2010.11.003

73. Engler HS, Fernandez A, Bliven FE, Moretz WH. Cancer arising in scars of old burns and in chronic osteomyelitis, ulcers, and drainage sites. Surgery. 1964;55:654-64. DOI:

74. Pfarschner W. Fistulous cancer in chronic osteomyelitis in its pathogenetic and histological aspects. Dtsch Med J. 1964;15:2007. DOI:

75. Samaras V, Rafailidis PI, Mourtzoukou EG, Peppas G, Falagas ME. Chronic bacterial and parasitic infections and cancer: a review. J Infect Dev Ctries. 2010;4(5):267-81. D0I: 10.3855/jidc.819

76. Botelho MC, Richter J. Editorial: Parasites and Cancer. Front Med. 2019;6:55. DOI: 10.3389/fmed.2019.00055

77. Schwartz DA. Helminths in the induction of cancer II. Schistosoma haematobium and bladder cancer. Trop Geogr Med. 1981;33(1):17. DOI:

78. Kim TS, Pak JH, Kim JB, Bahk YY, Oh JK, Weiderpass E, et al. Clonorchis sinensis, an oriental liver fluke, as a human biological agent of cholangiocarcinoma: a brief review. BMB Rep. 2016;49(11):590-7. DOI: 10.5483/bmbrep.2016.49.11.109.

79. Sripa B, Brindley PJ, Mulvenna J, Laha T, Smout MJ, Mairiang E, et al. The tumorigenic liver fluke Opisthorchis viverrini--multiple pathways to cancer. The systematics and population genetics of Opisthorchis viverrini sensu lato: implications in parasite epidemiology and bile duct cancer. Trends Parasitol. 2012;28(10):395-407. DOI: 10.1016/j.pt.2012.07.006
80. Muehlenbachs A, Bhatnagar J, Agudelo CA, Hidron A, Eberhard ML, Mathison BA, et al. Malignant Transformation of Hymenolepis nana in a Human Host. New Eng J Med. 2015;373(19):1845-52. DOI: 10.1056/NEJMoa1505892

81. Gross L. Viral etiology of cancer, leukemia and allied diseases. CA Cancer J Clin. 1970;20(4):242-7. DOI: 10.3322/canjclin.20.4.242

82. Yamagiwa $K_{1}$ Ichikawa K. Experimental study of the pathogenesis of carcinoma. CA Cancer J Clin. 1977;27(3):174-81. DOI: 10.3322/ canjclin.27.3.174

83. Pulciani $S$, Santos E, Lauver AV, Long LK, Robbins KC, Barbacid M. Oncogenes in human tumor cell lines: molecular cloning of a transforming gene from human bladder carcinoma cells. Proc Natl Acad Sci U S A. 1982;79(9):2845-9. DOI: 10.1073/pnas.79.9.2845

84. Goldfarb $M$, Shimizu $K$, Perucho $M$, Wigler M. Isolation and preliminary characterization of a human transforming gene from T24 bladder carcinoma cells. Nature. 1982;296(5856):404-9. DOI: 10.1038/296404a0

85. Boveri T. Zur Frage der Entstehung maligner Tumoren. Info at: https://wwwworldcatorg/title/zur-frage-der-entstehung-maligner-tumoren/oclc/10215868. 1914. DOI:

86. Shih $\mathrm{C}$, Weinberg RA. Isolation of a transforming sequence from a human bladder carcinoma cell line. Cell. 1982;29(1):161-9. D0I: 10.1016/0092-8674(82)90100-3

87. Yap TA, Plummer R, Azad NS, Helleday T. The DNA Damaging Revolution: PARP Inhibitors and Beyond. American Society of Clinical Oncology educational book American Society of Clinical Oncology Annual Meeting. 2019;39:185-95. DOI: 10.1200/edbk_238473

88. Lecona E, Fernandez-Capetillo 0. Targeting ATR in cancer. Nature reviews Cancer. 2018;18(9):586-95. DOI: 10.1038/s41568-0180034-3

89. de Martel C, Ferlay J, Franceschi S, Vignat J, Bray F, Forman D, et al. Global burden of cancers attributable to infections in 2008: a review and synthetic analysis. Lancet Oncol. 2012;13(6):607-15. DOI: 10.1016/s1470-2045(12)70137-7

90. Garcia-Villanueva S, Dominguez-Gil Gonzalez M, Gayete Martinez J, Munoz Bellido JL, Salas Valien JS, Echevarria Iturbe C, et al. Comparative study of the prevalence of the human papilloma virus in Spanish and foreign women participating in a population screening programme in Castilla y Leon. Enferm Infecc Microbiol Clin. 2019;37(5):314-8. DOI: 10.1016/j.eimc.2018.09.007

91. Small $W_{1}$ Jr., Bacon MA, Bajaj $A$, Chuang LT, Fisher BJ, Harkenrider $\mathrm{MM}$, et al. Cervical cancer: A global health crisis. Cancer. 2017;123(13):2404-12. DOI: 10.1002/cncr.30667

92. Romano L, Paladini S, Galli C, Raimondo G, Pollicino T, Zanetti AR. Hepatitis B vaccination. Hum Vaccin Immunother 2015;11(1):53-7. DOI: $10.4161 /$ hv.34306

93. Danaei G. Global burden of infection-related cancer revisited. Lancet Oncol. 2012;13(6):564-5. DOI: 10.1016/s1470-2045(12)701766

94. de Martel C, Shiels MS, Franceschi S, Simard EP, Vignat J, Hall HI, et al. Cancers attributable to infections among adults with HIV in the United States. AIDS (London, England). 2015;29(16):2173-81. D0I: 10.1097/qad.0000000000000808 


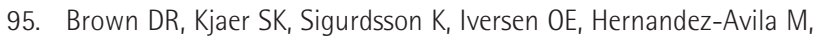

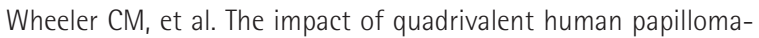
virus (HPV; types 6, 11, 16, and 18) L1 virus-like particle vaccine on infection and disease due to oncogenic nonvaccine HPV types in generally HPV-naive women aged 16-26 years. J Infect Dis. 2009;199(7):926-35. DOI: 10.1086/597307

96. Eltoum IA, Roberson J. Impact of HPV testing, HPV vaccine development, and changing screening frequency on national Pap test volume: projections from the National Health Interview Survey (NHIS). Cancer. 2007;111(1):34-40. DOI: 10.1002/cncr.22487

97. Luostarinen T, Apter D, Dillner J, Eriksson T, Harjula K, Natunen K, et al. Vaccination protects against invasive HPV-associated cancers. Int J Cancer. 2018;142(10):2186-7. DOI: 10.1002/ijc.31231

98. Guo F, Cofie LE, Berenson AB. Cervical Cancer Incidence in Young U.S. Females After Human Papillomavirus Vaccine Introduction. Am J Prev Med. 2018;55(2):197-204. DOI: 10.1016/j.amepre.2018.03.013

99. de Sanjosé S, Serrano B, Tous S, Alejo M, Lloveras B, Quirós B, et al. Burden of Human Papillomavirus (HPV)-Related Cancers Attributable to HPVs 6/11/16/18/31/33/45/52 and 58. JNCl Cancer Spectr. 2018;2(4):pky045. DOI: 10.1093/jncics/pky045

100. Drolet M, Benard E, Perez N, Brisson M. Population-level impact and herd effects following the introduction of human papillomavirus vaccination programmes: updated systematic review and meta-analysis. Lancet (London, England). 2019;394(10197):497-509. DOI: 10.1016/s0140-6736(19)30298-3

101. Markowitz LE, Naleway AL, Lewis RM, Crane B, Querec TD, Weinmann $\mathrm{S}$, et al. Declines in HPV vaccine type prevalence in women screened for cervical cancer in the United States: Evidence of direct and herd effects of vaccination. Vaccine. 2019;37(29):3918-24. DOI: 10.1016/j.vaccine.2019.04.099

102. Palmer T, Wallace L, Pollock KG, Cuschieri K, Robertson C, Kavanagh $K$, et al. Prevalence of cervical disease at age 20 after immunisation with bivalent HPV vaccine at age 12-13 in Scotland: retrospective population study. BMJ (Clinical research ed). 2019;365:I1161. DOI: 10.1136/bmj.l1161

103. Reig M, Boix L, Mariño Z, Torres F, Forns X, Bruix J. Liver Cancer Emergence Associated with Antiviral Treatment: An Immune Surveillance Failure? Semin Liver Dis. 2017;37(2):109-18. DOI: 10.1055/s-0037-1601349

104. Reig M, Boix L, Bruix J. The impact of direct antiviral agents on the development and recurrence of hepatocellular carcinoma. Liver Int. 2017;37 Suppl 1:136-9. DOI: 10.1111/liv.13321

105. Reig M, Torres F, Mariño Z, Forns X, Bruix J. Reply to "Direct antiviral agents and risk for hepatocellular carcinoma (HCC) early recurrence: Much ado about nothing". J Hepatol. 2016;65(4):864-5. DOI: 10.1016/j.jhep.2016.05.036

106. Reig $M$, Mariño $Z$, Perelló $C$, Iñarrairaegui $M$, Ribeiro $A$, Lens $S$, et al. Unexpected high rate of early tumor recurrence in patients with HCV-related HCC undergoing interferon-free therapy. J Hepatol. 2016;65(4):719-26. DOI: 10.1016/j.jhep.2016.04.008

107. Younossi ea. Clinical Gastroenterology and Hepatology. Google Scholar. 2019;Lin at: https://scholar.google.co.uk/schol-
ar?q=Younossi ++ Gastro+Hepatol +2019 \&thl $=$ enctas_sdt=0\&tas_ vis $=1$ \&oi $=$ scholart\&tsafe $=$ active.

108. Scheffler RW. Following cancer viruses through the laboratory, clinic, and society. Studies in history and philosophy of biological and biomedical sciences. 2014;48 Pt B:185-8. DOI: 10.1016/j.shpsc.2014.09.004

109. Lang Kuhs KA, Porras $C$, Schiller JT, Rodriguez AC, Schiffman $M$, Gonzalez $\mathrm{P}$, et al. Effect of different human papillomavirus serological and DNA criteria on vaccine efficacy estimates. Am J Epidemiol. 2014;180(6):599-607. DOI: 10.1093/aje/kwu168

110. Read SA, Douglas MW. Virus induced inflammation and cancer development. Cancer Lett. 2014;345(2):174-81. DOI: 10.1016/j.canlet.2013.07.030

111. Fuentes-Gonzalez AM, Contreras-Paredes A, Manzo-Merino J, Lizano $\mathrm{M}$. The modulation of apoptosis by oncogenic viruses. Virol J. 2013;10:182. DOI: 10.1186/1743-422x-10-182

112. Butt AQ, Miggin SM. Cancer and viruses: a double-edged sword. Proteomics. 2012;12(13):2127-38. DOI: 10.1002/pmic.201100526

113. Hoppe-Seyler F, Hoppe-Seyler K. Emerging topics in human tumor virology. Int J Cancer. 2011;129(6):1289-99. DOI: 10.1002/ijc.26087

114. Moore PS, Chang Y. Why do viruses cause cancer? Highlights of the first century of human tumour virology. Nat Rev Cancer. 2010;10(12):878-89. DOI: 10.1038/nrc2961

115. Shors T. "Los virus y el cáncer", en Virus. Estudio molecular con orientación clínica, Buenos Aires, Editorial Médica Panamericana, pp. 242-279. [cited 10 April 2021]: https://wwwresearchgatenet/ publication/324597928_Virus_y_Cancer. 2009.

116. van Zyl DG, Mautner J, Delecluse HJ. Progress in EBV Vaccines. Front Oncol. 2019;9:104. DOI: 10.3389/fonc.2019.00104

117. Cohen Jl. Epstein-barr virus vaccines. Clin Transl Immunol. 2015;4(1):e32. DOI: 10.1038/cti.2014.27

118. Young LS, Dawson CW. Epstein-Barr virus and nasopharyngeal carcinoma. Chin J Cancer. 2014;33(12):581-90. DOI: 10.5732/ cjc.014.10197

119. Taylor GS, Long HM, Brooks JM, Rickinson AB, Hislop AD. The immunology of Epstein-Barr virus-induced disease. Annu Rev Immunol. 2015;33:787-821. DOI: 10.1146/annurev-immunol-032414-112326

120. Taylor GS, Steven NM. Therapeutic vaccination strategies to treat nasopharyngeal carcinoma. Chin Clin Oncol. 2016;5(2):23. DOI: 10.21037/cco.2016.03.20

121. Yao Y, Minter HA, Chen $X$, Reynolds GM, Bromley M, Arrand JR. Heterogeneity of HLA and EBER expression in Epstein-Barr virus-associated nasopharyngeal carcinoma. Int J Cancer. 2000;88(6):949-55. D0I: 10.1002/1097-0215(20001215)88:6<949::aid-ijc18>3.0.co;2-6

122. Hong M, Tang $K$, Qian J, Deng $H$, Zeng M, Zheng $S$, et al. Immunotherapy for EBV-Associated Nasopharyngeal Carcinoma. Crit Rev Oncog. 2018;23(3-4):219-34. DOI: 10.1615/CritRevOncog. 2018027528

123. Lin $C L$, Lo WF, Lee TH, Ren $Y$, Hwang SL, Cheng YF, et al. Immunization with Epstein-Barr Virus (EBV) peptide-pulsed dendritic cells induces functional CD8+ T-cell immunity and may lead to tumor 
regression in patients with EBV-positive nasopharyngeal carcinoma. Cancer Res. 2002;62(23):6952-8. D0I:

124. Chia WK, Wang WW, Teo M, Tai WM, Lim WT, Tan EH, et al. A phase II study evaluating the safety and efficacy of an adenovirus- $\triangle$ LMP1-LMP2 transduced dendritic cell vaccine in patients with advanced metastatic nasopharyngeal carcinoma. Ann Oncol. 2012;23(4):997-1005. DOI: 10.1093/annonc/mdr341

125. Hui EP, Taylor GS, Jia H, Ma BB, Chan SL, Ho R, et al. Phase I trial of recombinant modified vaccinia ankara encoding Epstein-Barr viral tumor antigens in nasopharyngeal carcinoma patients. Cancer Res. 2013;73(6):1676-88. DOI: 10.1158/0008-5472.Can-12-2448

126. Taylor GS, Jia H, Harrington K, Lee LW, Turner J, Ladell K, et al. A recombinant modified vaccinia ankara vaccine encoding Epstein-Barr Virus (EBV) target antigens: a phase I trial in UK patients with EBV-positive cancer. Clin Cancer Res. 2014;20(19):5009-22. DOI: 10.1158/1078-0432.Ccr-14-1122-t

127. Rees L, Tizard EJ, Morgan AJ, Cubitt WD, Finerty S, Oyewole-Eletu TA, et al. A phase I trial of epstein-barr virus gp350 vaccine for children with chronic kidney disease awaiting transplantation. Transplantation. 2009;88(8):1025-9. DOI: 10.1097/TP.0b013e3181b9d918

128. Lockey TD, Zhan X, Surman S, Sample CE, Hurwitz JL. Epstein-Barr virus vaccine development: a lytic and latent protein cocktail. Front Biosci. 2008;13:5916-27. DOI: 10.2741/3126

129. Elliott SL, Suhrbier A, Miles JJ, Lawrence G, Pye SJ, Le T, et al. Phase I trial of a CD8+ T-cell peptide epitope-based vaccine for infectious mononucleosis. J Virol. 2008;82(3):1448-57. DOI: 10.1128/ jvi.01409-07

130. Lunde $E_{1}$ Bogen B, Sandlie I. Immunoglobulin as a vehicle for foreign antigenic peptides immunogenic to T cells. Mol Immunol. 1997;34(16-17):1167-76. DOI: 10.1016/s0161-5890(97)00143-0

131. Kanekiyo M, Bu W, Joyce MG, Meng G, Whittle JR, Baxa U, et al. Rational Design of an Epstein-Barr Virus Vaccine Targeting the Receptor-Binding Site. Cell. 2015;162(5):1090-100. DOI: 10.1016/j. cell.2015.07.043

132. Ogembo JG, Muraswki MR, McGinnes LW, Parcharidou A, Sutiwisesak $R$, Tison T, et al. A chimeric EBV gp350/220-based VLP replicates the virion B-cell attachment mechanism and elicits long-lasting neutralizing antibodies in mice. J Transl Med. 2015;13:50. DOI: 10.1186/s12967-015-0415-2

133. Perez EM, Foley J, Tison T, Silva R, Ogembo JG. Novel Epstein-Barr virus-like particles incorporating $\mathrm{gH} / \mathrm{gL}-\mathrm{EBNA} 1$ or gB-LMP2 induce high neutralizing antibody titers and EBV-specific T-cell responses in immunized mice. Oncotarget. 2017;8(12):19255-73. DOI: 10.18632/oncotarget.13770

134. Ruiss R, Jochum S, Wanner G, Reisbach G, Hammerschmidt W, Zeidler R. A virus-like particle-based Epstein-Barr virus vaccine. J Virol. 2011;85(24):13105-13. DOI: 10.1128/jvi.05598-11

135. Delecluse HJ, Pich D, Hilsendegen T, Baum C, Hammerschmidt W. A first-generation packaging cell line for Epstein-Barr virus-derived vectors. Proc Natl Acad Sci U S A. 1999;96(9):5188-93. DOI: 10.1073/pnas.96.9.5188

136. Feederle R, Shannon-Lowe C, Baldwin G, Delecluse HJ. Defective infectious particles and rare packaged genomes produced by cells carrying terminal-repeat-negative epstein-barr virus. J Virol. 2005;79(12):7641-7. DOI: 10.1128/jvi.79.12.7641-7647.2005

137. Neuhierl B, Feederle R, Hammerschmidt W, Delecluse HJ. Glycoprotein gp110 of Epstein-Barr virus determines viral tropism and efficiency of infection. Proc Natl Acad Sci U S A. 2002;99(23):1503641. DOI: $10.1073 /$ pnas.232381299

138. Raja J, Ludwig JM, Gettinger SN, Schalper KA, Kim HS. Oncolytic virus immunotherapy: future prospects for oncology. J Immunother Cancer. 2018;6(1):140. DOI: 10.1186/s40425-018-0458-Z

139. Russell L, Peng KW. The emerging role of oncolytic virus therapy against cancer. Chin Clin Oncol. 2018;7(2):16. DOI: 10.21037/ cco.2018.04.04

140. Russell SJ, Peng KW. The utility of cells as vehicles for oncolytic virus therapies. Curr Opin Mol Ther. 2008;10(4):380-6. DOI:

141. Larocca C, Schlom J. Viral vector-based therapeutic cancer vaccines. Cancer J. 2011;17(5):359-71. DOI: 10.1097/PPO. 0b013e3182325e63

142. Bommareddy PK, Patel A, Hossain S, Kaufman HL. Talimogene Laherparepvec (T-VEC) and Other Oncolytic Viruses for the Treatment of Melanoma. Am J Clin Dermatol. 2017;18(1):1-15. DOI: 10.1007/ s40257-016-0238-9

143. Liu BL, Robinson M, Han ZO, Branston RH, English C, Reay $P$, et al. ICP34.5 deleted herpes simplex virus with enhanced oncolytic, immune stimulating, and anti-tumour properties. Gene Ther. 2003;10(4):292-303. DOI: 10.1038/sj.gt.3301885

144. Drakes ML, Stiff PJ. Harnessing immunosurveillance: current developments and future directions in cancer immunotherapy. Immunotargets Ther. 2014;3:151-65. DOI: 10.2147/itt.S37790

145. Antonarakis ES. Combining active immunotherapy with immune checkpoint blockade for the treatment of advanced prostate cancer. Asian J Androl. 2012;14(4):520-1. D0I: 10.1038/aja.2012.45

146. Parato KA, Breitbach CJ, Le Boeuf F, Wang J, Storbeck C, Ilkow C, et al. The oncolytic poxvirus JX-594 selectively replicates in and destroys cancer cells driven by genetic pathways commonly activated in cancers. Mol Ther. 2012;20(4):749-58. DOI: 10.1038/mt.2011.276

147. Xie Y, Xiang Y, Sheng J, Zhang D, Yao X, Yang Y, et al. Immunotherapy for Hepatocellular Carcinoma: Current Advances and Future Expectations. J Immunol Res. 2018;2018:8740976. DOI: $10.1155 / 2018 / 8740976$

148. Breitbach CJ, Arulanandam R, De Silva N, Thorne SH, Patt R, Daneshmand $M$, et al. Oncolytic vaccinia virus disrupts tumor-associated vasculature in humans. Cancer Res. 2013;73(4):1265-75. DOI: 10.1158/0008-5472.Can-12-2687

149. Yoo SY, Jeong SN, Kang DH, Heo J. Evolutionary cancer-favoring engineered vaccinia virus for metastatic hepatocellular carcinoma. Oncotarget. 2017;8(42):71489-99. DOI: 10.18632/oncotarget.17288

150. Goldufsky J, Sivendran S, Harcharik S, Pan M, Bernardo S, Stern $\mathrm{RH}$, et al. Oncolytic virus therapy for cancer. Oncolytic Virother. 2013;2:31-46. DOI: 10.2147/ov.S38901

151. Miyamoto S, Inoue H, Nakamura T, Yamada M, Sakamoto C, Urata Y, et al. Coxsackievirus B3 is an oncolytic virus with immunostimula- 
tory properties that is active against lung adenocarcinoma. Cancer Res. 2012;72(10):2609-21. DOI: 10.1158/0008-5472.Can-11-3185

152. Yaacov B, Eliahoo E, Lazar I, Ben-Shlomo M, Greenbaum I, Panet $A$, et al. Selective oncolytic effect of an attenuated Newcastle disease virus (NDV-HUJ) in lung tumors. Cancer Gene Ther. 2008;15(12):795-807. DOI: 10.1038/cgt.2008.31

153. Liu TC, Galanis E, Kirn D. Clinical trial results with oncolytic virotherapy: a century of promise, a decade of progress. Nat Clin Pract Oncol. 2007;4(2):101-17. DOI: 10.1038/ncponc0736

154. SEOM. Sociedad Española de Oncología Médica, Informe-SEOM-cifras-cancer. [cited 10 April 2021] http://wwwmedicosypacientescom/sites/default/files/Informe\%20SEOM-cifras-cancer2019pdf. 2019.

155. Lopez N, Torne A, Franco A, San-Martin M, Viayna E, Barrull C, et al. Epidemiologic and economic burden of HPV diseases in Spain: implication of additional 5 types from the 9-valent vaccine. Infect Agents Cancer. 2018;13:15. DOI: 10.1186/s13027-018-0187-4

156. MSCYBS. Ministerio de Sanidad Consumo y Bienestar Social - Vacunación en grupos de riesgo de todas las edades y en determinadas situaciones. [cited 10 April 2021] https://wwwmscbsgobes/profesionales/saludPublica/prevPromocion/vacunaciones/VacGruposRiesgo/docs/VacGruposRiesgo_todas_las_edadespdf. 2018.

157. ACS. American Cancer Society - Global Cancer Facts \& Figures 4th Edition. [cited 10 April 2021] https://wwwcancerorg/content/dam/ cancer-org/research/cancer-facts-and-statistics/global-cancerfacts-and-figures/global-cancer-facts-and-figures-4th-editionpdf. 2018.

158. NIH. Germenes infecciosos. Instituto Nacional del Cancer. 2010; [cited 10 April 2021] https://www.cancer.gov/espanol/cancer/causas-prevencion/riesgo/germenes-infecciosos.

159. ACS. American Cancer Society. (09/10/2017) y VPH y cancer. 16/01/2020,. [cited 10 April 2021] - https://wwwcancerorg/cancer/ cancer-causes/infectious-agents/hpv/hpv-and-cancer-infohtml. 2017.:

160. NIH. Institute Nacional del Cancer. (01/03/2019). VPH y el cancer. 16/01/2020, de Institute Nacional del Cancer. [cited 10 April 2021] https://wwwcancergov/espanol/cancer/causas-prevencion/riesgo/ germenes-infecciosos/vph-y-cancer. 2019, 2020. 